\title{
HSRL-2 aerosol optical measurements and microphysical retrievals vs. airborne in situ measurements during DISCOVER-AQ 2013: an intercomparison study
}

Patricia Sawamura $^{1,2}$, Richard H. Moore ${ }^{1}$, Sharon P. Burton ${ }^{1}$, Eduard Chemyakin ${ }^{1,3}$, Detlef Müller ${ }^{4,3}$, Alexei Kolgotin ${ }^{5}$, Richard A. Ferrare ${ }^{1}$, Chris A. Hostetler ${ }^{1}$, Luke D. Ziemba ${ }^{1}$, Andreas J. Beyersdorf ${ }^{1}$, and Bruce E. Anderson ${ }^{1}$

${ }^{1}$ NASA Langley Research Center, Hampton, VA, USA

${ }^{2}$ Universities Space Research Association, Columbia, MD, USA

${ }^{3}$ Science Systems and Applications, Inc., Hampton, VA, USA

${ }^{4}$ University of Hertfordshire, Hatfield, Hertfordshire, UK

${ }^{5}$ Physics Instrumentation Center, Troitsk, Russia

Correspondence to: P. Sawamura (patricia.sawamura@nasa.gov)

\begin{abstract}
Over 700 vertically-resolved retrievals of effective radii, number, volume, and surface-area concentrations of aerosols obtained from inversion of airborne multiwavelength High Spectral Resolution Lidar (HSRL-2) measurements are compared to vertically resolved airborne in situ measurements obtained during DISCOVER-AQ campaign from 2013 in California and Texas. In situ measurements of dry and humidified scattering, dry absorption, and dry size distributions are used to estimate 5 hygroscopic adjustments which, in turn, are applied to the dry in situ measurements before comparison to HSRL-2 measurements and retrievals. The HSRL-2 retrievals of size parameters agree well with the in situ measurements once the hygroscopic adjustments are applied to the latter, with biases smaller than $25 \%$ for surface-area concentrations, and smaller than $10 \%$ for volume concentration. A closure study is performed by comparing the extinction and backscatter measured with the HSRL-2 with those calculated from the in situ size distributions and Mie theory, once refractive indices (at ambient RH) and hygroscopic adjustments are calculated and applied. The results of this closure study revealed discrepancies between the HSRL-2 optical measurements and those calculated from in situ measurements, in both California and Texas datasets, with the aerosol extinction and backscatter coefficients measured with the HSRL-2 being larger than those calculated from the adjusted in situ measurements and Mie theory. These discrepancies are further investigated and discussed in light of the many challenges often present in closure studies between in situ and remote sensing systems, such as: limitations in covering the same size range of particles with in situ and remote sensing instruments, as well as simplified parameterizations and assumptions used when dry in situ data are adjusted to account for aerosol hygroscopicity.
\end{abstract}

\section{Introduction}

In situ and remote sensing airborne measurements are of fundamental importance for the study of aerosol-cloud-climate interactions (McFarquhar et al., 2011; Baumgardner et al., 2011). Ground- and space-based observations are just as important, 
Atmos. Chem. Phys. Discuss., doi:10.5194/acp-2016-380, 2016

Atmospheric

Chemistry

Published: 17 May 2016

(c) Author(s) 2016. CC-BY 3.0 License.

and Physics

Discussions

(c) (i)

but are not enough for providing a comprehensive observational basis to evaluate and improve air quality and climate models. Ground-based observations are very helpful for studying the temporal evolution of aerosol and clouds with higher temporal resolution than satellite measurements can provide, but they lack in spatial coverage. Satellites, on the other hand, provide measurements over a wider spatial range but suffer from the low temporal resolution of measurements obtained at any particular location on the globe. Aircraft measurements offer a solution to bridge this gap between ground- and space-based observations, and are also important for testing the feasibility of future space-borne instruments.

However, as McFarquhar et al. (2011) point out, more effort is needed to improve our current understanding of the caveats and uncertainties associated with airborne measurements. Kassianov et al. (2015) emphasize the importance of closure studies to ensure consistency among the many different measurements that can be obtained from an airborne platform.

Comprehensive observations of aerosol optical and microphysical properties are also critical for developing and evaluating aerosol transport model parameterizations and assessing global aerosol-radiation impacts on climate. Lidars, in particular, are important tools for atmospheric measurements as they are able to provide detailed information on the vertical distribution of aerosols.

NASA Langley Research Center's HSRL-2 (High Spectral Resolution Lidar-2) is a unique airborne system that provides a complete $3 \beta+2 \alpha$ data set (i.e. 3 backscatter +2 extinction) that allows the retrieval of horizontally- and vertically-resolved aerosol physical properties, such as number, surface-area, and volume concentrations, as well as effective radius, in addition to the multiwavelength optical properties (Müller et al., 2014). HSRL-2 is also a prototype for the spaceborne lidar system being considered for the ACE (Aerosol-Cloud-Ecosystem) mission (http://dsm/gsfc.nasa.gov/ace) which has the objective of improving our understandings of the interactions among aerosols, cloud and precipitation systems, and ocean ecosystems.

A number of studies have focused in the $3 \beta+2 \alpha$ retrieval technique in the past decade (Müller et al., 1998, 2001; Wandinger et al., 2002; Müller et al., 2003; Murayama et al., 2004; Müller et al., 2006; Tesche et al., 2008; Noh et al., 2009; Balis et al., 2010; Alados-Arboledas et al., 2011; Navas-Guzmán et al., 2013; Nicolae et al., 2013; Sawamura et al., 2014), most of which used data from ground-based Raman lidars. The validation of such retrievals, however, has always been a challenging task due to the unavailability of direct colocated measurements.

Direct measurements of aerosol size distributions, for instance, can only be obtained with in situ instruments. Most in situ measurements, however, are obtained at ground level, limiting the comparison to the few lidar retrievals that are obtained closest to the ground.

Other studies have compared the $3 \beta+2 \alpha$ lidar retrievals to AERONET (Aerosol Robotic Network, (Holben et al., 1998)) retrievals (Veselovskii et al., 2009; Sawamura et al., 2014). However, AERONET total column retrievals of volume concentrations are not directly comparable to vertically-resolved aerosol measurements, requiring an assumption that the aerosol is uniformly mixed throughout the boundary layer. Intercomparison studies between $3 \beta+2 \alpha$ lidar retrievals and AERONET retrievals or ground-based in situ measurements, therefore, are not suitable to properly evaluate the performance of the lidar microphysical retrievals obtained for different altitudes.

During DISCOVER-AQ, HSRL-2 and a suite of in situ instruments were deployed onboard two aircraft. The aircraft carrying the in situ instruments flew in spirals, providing vertical profiles of optical, physical, and chemical properties of aerosols. In this 
Atmos. Chem. Phys. Discuss., doi:10.5194/acp-2016-380, 2016

Atmospheric

Chemistry

Published: 17 May 2016

(c) Author(s) 2016. CC-BY 3.0 License.

and Physics

Discussions

(c) (i)

study we present the intercomparison of aerosol microphysical retrievals obtained with the HSRL-2 data to vertically-resolved in situ measurements obtained during two deployments of DISCOVER-AQ.

The hygroscopicity of aerosols represents a challenge for comparison studies like this, i.e. lidar vs. in situ (Zieger et al., 2010, 2011; Sawamura et al., 2014). At high relative humidities aerosol particles experience changes in size which in turn translates

5 into changes in their optical properties. These changes depend on the aerosol chemical composition and also on the ambient relative humidity $(\mathrm{RH})$. Remote sensing measurements, like those from HSRL-2, are obtained under ambient conditions. In situ measurements, on the other hand, are usually obtained under dry conditions (low relative humidity). Therefore, in order to avoid an unrepresentative comparison to lidar measurements and/or retrievals, in situ measurements have to be adjusted to account for hygroscopic effects.

Müller et al. (2014) presented the first results of microphysical retrievals from HSRL-2 data obtained during the TwoColumn Aerosol Project (TCAP) (Berg et al., 2016). During TCAP, the aircraft carrying the in situ instruments flew in spirals on 2 days, allowing the comparison of a full profile (up to $\sim 4 \mathrm{~km}$ ) of colocated in situ measurements and lidar retrievals of number, surface-area, and volume concentration, as well as effective radii. For this specific comparison case, hygroscopic adjustments were not necessary. Good agreement was observed between the HSRL-2 retrievals and the in situ measurements.

In this study we present a methodology to adjust the in situ measurements to account for aerosol hygroscopicity and discuss the results from the comparison of more than 700 lidar retrievals of size parameters, i.e. number, surface-area, and volume concentrations, and effective radius, to colocated in situ measurements obtained during DISCOVER-AQ 2013. We analyze approximately 110 colocated profiles of HSRL-2 retrievals and in situ measurements $(700+$ sets of $3 \beta+2 \alpha)$, making this the largest study to date on the evaluation of microphysical retrievals obtained from multiwavelength lidar measurements.

In a closure study, backscatter and extinction coefficients were calculated using the in situ size distributions already adjusted to ambient RH, the corresponding adjusted refractive indices, and Mie theory. These calculated optical data set are then compared to the measurements obtained by the HSRL-2 and the results are analyzed and discussed in light of the many challenges that are often present in studies of this kind, such as: limitations in covering the same size range of particles with in situ and remote sensing instruments, as well as simplified parameterizations and assumptions used when dry in situ data are adjusted to account for aerosol hygroscopicity.

\section{DISCOVER-AQ}

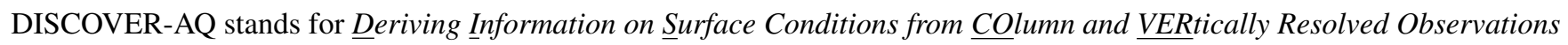
Relevant to Air Quality. For brevity we will refer to DISCOVER-AQ as DAQ for the remainder of this paper. DAQ was a 4-year NASA project with the objective of improving the interpretation of total-column satellite observations to help diagnose near-surface conditions relating to air quality. DAQ took place in Baltimore-Washington D.C. in the Summer 2011, in San Joaquin Valley, California and Houston, Texas in Winter and Summer 2013, respectively, and in the Colorado Front Range in Summer 2014. 
Atmos. Chem. Phys. Discuss., doi:10.5194/acp-2016-380, 2016

Atmospheric

Chemistry

Published: 17 May 2016

(c) Author(s) 2016. CC-BY 3.0 License.

and Physics

Discussions

(c) (i)

In this study we use data from the 2013 deployments in California (DAQ CA: Jan/Feb 2013) and Texas (DAQ TX: Aug/Sep 2013).

During DAQ 2013, HSRL-2 was flown onboard the NASA Langley B200 King Air aircraft downward-looking at approximately $8.5 \mathrm{~km}$ altitude. Many in situ instruments were flown onboard NASA Wallops P-3B aircraft which spiraled up and down over several designated ground stations from altitudes as low as $15 \mathrm{~m}$ up to about $5 \mathrm{~km}$. The two aircraft followed coordinated flight tracks, both flying over the designated air quality monitoring ground stations with close time coincidence, allowing for colocation of measurements from the in situ instruments suite and the HSRL-2. Figure 1 shows maps of the King Air and P-3B aircraft flight tracks during DAQ California and Texas, as well as the designated ground stations.

\section{LaRC HSRL-2}

HSRL-2 follows in the heritage of the successful airborne instrument HSRL-1 (Hair et al., 2008) which independently measures the aerosol extinction and backscatter at $532 \mathrm{~nm}$ with the HSRL technique (Shipley et al., 1983), and the backscatter at 1064 $\mathrm{nm}$ with the standard backscatter lidar technique (Fernald, 1984). HSRL-1 also measures aerosol depolarization ratio at 532 $\mathrm{nm}$ and $1064 \mathrm{~nm}$.

HSRL-2 provides independent measurements of aerosol extinction and backscatter at 355 nm using the HSRL technique, and depolarization ratio at $355 \mathrm{~nm}$, in addition to the measurements that can be obtained with HSRL-1. These new capabilities make HSRL-2 the first airborne system that provides a complete $3 \beta+2 \alpha$ dataset (i.e. 3 backscatter +2 extinction) from which microphysical properties of aerosols can be retrieved (Qing et al., 1989; Müller et al., 1999a).

HSRL-2 data are sampled at temporal resolution of 0.5 second and vertical resolution of 15 meters. Aerosol backscatter and depolarization products are horizontally averaged for 10 seconds ( $\sim 1 \mathrm{~km}$ at nominal aircraft speed) and aerosol extinction products are averaged for 60 seconds $(\sim 6 \mathrm{~km})$. The microphysical data products were retrieved at vertical resolution of $150 \mathrm{~m}$ during DISCOVER-AQ Texas and 75 m during DISCOVER-AQ California due to shallow planetary boundary layers observed throughout the campaign.

\subsection{Inversion algorithm}

The inversion method used for the retrievals is based on the concepts described by Müller et al. (1999a) and Veselovskii et al. (2002) and uses the backscatter measurements at 355, 532 and $1064 \mathrm{~nm}$ and extinction measurements at 355 and $532 \mathrm{~nm}$. The original inversion method has been successfully applied to a number of case studies by many lidar groups in the last decades (Müller et al., 1998, 2001; Wandinger et al., 2002; Müller et al., 2003; Murayama et al., 2004; Müller et al., 2006; Tesche et al., 2008; Noh et al., 2009; Balis et al., 2010; Alados-Arboledas et al., 2011; Navas-Guzmán et al., 2013; Nicolae et al., 2013; Sawamura et al., 2014).

The inversion method used with the HSRL-2 data, however, has been modified to allow automated and unsupervised processing of large volumes of data. The algorithm is described by Müller et al. (2014) which we briefly review here. 
Atmos. Chem. Phys. Discuss., doi:10.5194/acp-2016-380, 2016

Manuscript under review for journal Atmos. Chem. Phys.

The equations that relate the measured aerosol optical properties (i.e. $3 \beta+2 \alpha$ ) to the aerosol's inherent microphysical properties, such as size distribution and complex refractive index, are solved under the assumption that the size distributions can be reconstructed as linear combinations of eight logarithmically equidistant triangular-shaped base functions within an inversion window (Müller et al., 1999a, b). We use a comparably wide range of parameters in the inversion windows, i.e. particle radius from 0.03 - 8 mum, real part of the complex refractive index from $1.325-1.8$, and imaginary part from 0 - 0.1 . In order to stabilize the retrieval results we therefore apply extra constraints to the solution spaces. For that purpose we use the inversion results we have for particle effective radius and number concentration. We compute the mean values of effective radius and number concentration from the individual solutions. We then reject the individual solutions that deviate too much from the mean values of effective radius and number concentration, respectively. The threshold value with regard to deviation of individual solutions from mean values was set to $25 \%$-deviation for effective radius and $100 \%$ for number concentration. The discrepancy averaging interval was set to less than $10 \%$. The computations are parallelized to increase the speed of the data inversion process.

For each $3 \beta+2 \alpha$ set the algorithm is run 9 times. In 8 of those runs, the extinction and backscatter coefficients input are distorted by their respective uncertainties in different combinations in order to simulate possible measurement error scenarios (see Table 1). Another run is performed with error-free input data. Hundreds of thousands of solutions are obtained with those 9 runs. The 500 solutions with the lowest discrepancies are averaged and stored as the final solution (Müller et al., 1999b; Veselovskii et al., 2002). The standard deviation of those 500 best solutions is assumed to be a good measure of the retrieval uncertainty.

Only $3 \beta+2 \alpha$ sets with uncertainties below $20 \%$ are used for the inversion (Müller et al., 1999b). The uncertainties originate from the HSRL-2 system's random noise and are estimated using the noise scale factor methodology described by Liu et al. (2006).

\section{In situ instruments}

The aerosol size distribution and optical properties are measured in situ by the P-3B aircraft by the NASA Langley Aerosol Research Group (LARGE). Aerosols are sampled isokinetically via a low-turbulence inlet mounted on the port side of the aircraft that is able to transmit particles smaller than $5 \mu \mathrm{m}$ diameter (50\% cutoff efficiency) (McNaughton et al., 2007). The sampling stream is then brought into the cabin and split between multiple instruments, only a subset of which are briefly described here.

Aerosol dry and humidified light scattering coefficients at 450, 550, and $700 \mathrm{~nm}$ wavelength are measured by two integrating nephelometers (Model 3563, TSI, Inc., Shoreview, MN, USA) operated in tandem (Pilat and Charlson, 1966; Clarke et al., 2002; Ziemba et al., 2013). The measurements are corrected for truncation errors following Anderson and Ogren (1998). One 
Atmos. Chem. Phys. Discuss., doi:10.5194/acp-2016-380, 2016

Atmospheric

Manuscript under review for journal Atmos. Chem. Phys.

Chemistry

Published: 17 May 2016

(c) Author(s) 2016. CC-BY 3.0 License.

and Physics

Discussions

(c) (i)

of the nephelometers is operated at dry relative humidity $(\mathrm{RH}<40 \%)$, while the other is operated at elevated relative humidity ( $\mathrm{RH}=80-85 \%$ during DAQ). These measurements are used to derive the aerosol hygroscopicity parameter, $\gamma$, as

$\gamma=\frac{\ln \left(\frac{\sigma_{\mathrm{scat}, \mathrm{wet}}}{\sigma_{\mathrm{scat}, \mathrm{dry}}}\right)}{\ln \left(\frac{100-\mathrm{RH}_{\mathrm{dry}}}{100-\mathrm{RH}_{\mathrm{wet}}}\right)}$

where $\sigma_{\text {scat,dry }}$ and $\sigma_{\text {scat,wet }}$ are the aerosol light scattering coefficients under dry $\left(\mathrm{RH}_{d r y}\right)$ and elevated $\mathrm{RH}$ conditions $5\left(\mathrm{RH}_{\text {wet }}\right)$, respectively.

The ambient RH outside the aircraft is computed using the aircraft static temperature measurement and water vapor concentration measured by an open-path diode laser hygrometer (Diskin et al., 2002), and the ambient aerosol scattering coefficient $\sigma_{\text {scat }, a m b}$ at this $\mathrm{RH}_{a m b}$ is then determined as

$\sigma_{\text {scat }, \mathrm{amb}}\left(\mathrm{RH}_{\mathrm{amb}}\right)=\sigma_{\text {scat,dry }}\left[\frac{100-\mathrm{RH}_{\mathrm{dry}}}{100-\mathrm{RH}_{\mathrm{amb}}}\right]^{\gamma}$

This transformation is important for comparing the in situ light scattering measurements to those from the HSRL-2 because sampling aerosols in situ using an isokinetic inlet and bringing the sample stream into the warm cabin inherently changes the particle temperature and, hence the relative humidity, while the HSRL measures the aerosol scattering and extinction under unperturbed, ambient conditions.

The accuracy of the $\gamma$ parameter fitting method (Kasten, 1969) has been questioned in the past and other multi-parameter methods have been suggested (Kotchenruther and Hobbs, 1998; Kotchenruther et al., 1999; Carrico et al., 2003; Brock et al., 2016). One of the limitations of the $\gamma$ parameterization is that, for instance, it cannot accurately describe the hygroscopic scattering enhancement $(\mathrm{f}(\mathrm{RH}))$ of particles that present abrupt phase transitions, like pure ammonium sulfate particles.

Dry aerosol absorption coefficients are measured at 450, 532, and $700 \mathrm{~nm}$ wavelength using a Particle Soot Absorption Photometer (PSAP; Radiance Research, Shoreline, WA, USA) that was heated to $30^{\circ} \mathrm{C}$ to prevent water condensation on the filter substrate. PSAP measurements are corrected for filter scattering following (Virkkula, 2010). Aerosol extinction coefficients are computed as the sum of the scattering and absorption coefficients, neglecting hydration effects on the absorption coefficient, which are highly uncertain and likely to be minimal for the largely non-absorbing aerosols observed during most of DAQ. The scattering Ångström exponent is used to adjust the $550 \mathrm{~nm}$ scattering to $532 \mathrm{~nm}$ prior to the extinction coefficient calculation.

The aerosol dry size distribution is measured using two different optical particle counters: an Ultra-High Sensitivity Aerosol Spectrometer (UHSAS; Droplet Measurement Technologies, Inc., Boulder, CO, USA) that measures particles with diameters that range from $0.06 \mu \mathrm{m}$ to $1 \mu \mathrm{m}$, and a Laser Aerosol Spectrometer (LAS Model 3340; TSI, Inc.) that measures particles from $0.09 \mu \mathrm{m}$ to $7.5 \mu \mathrm{m}$ but it is limited by the cutoff size of the aircraft inlet, which in this case allows particles only up to $5 \mu \mathrm{m}$.

These instruments measure the intensity of light scattered from aerosol particles that pass through a focused laser beam. This intensity is proportional to the particle size and can be predicted with Mie theory (Mie, 1908) if the refractive index of the particles and the optical geometry of the instrument are known. Both instruments are field calibrated with NIST-traceable 
Atmos. Chem. Phys. Discuss., doi:10.5194/acp-2016-380, 2016

Manuscript under review for journal Atmos. Chem. Phys.

Published: 17 May 2016

(c) Author(s) 2016. CC-BY 3.0 License.
Atmospheric 을

Chemistry

and Physics

Discussions

(c) (i)

polystyrene latex spheres (ThermoScientific, Inc.). The refractive index of such particles ( $m_{P S L} \sim 1.588$ ), however, is higher than that of ambient aerosol particles.

The effect of the refractive index on optical counter measurements have been investigated and it was found that optical counters often undersize ambient particles. (Liu and Daum, 2000; Ames et al., 2000). Kassianov et al. (2015) demonstrate that ignoring the refractive index correction or using non-representative values can cause up to $40 \%$ in bias for the calculated scattering coefficient. For this reason, both instruments are also calibrated with monodisperse ammonium sulfate (AS) aerosols ( $m_{A S} \sim 1.53$ ) classified with a Differential Mobility Analyzer (DMA 3081, TSI, Inc.). For this study, we use the AS size calibration.

\section{Methodology}

Most of the in situ data used in this study were obtained at dry conditions $(\mathrm{RH}<40 \%)$, except for the scattering at $550 \mathrm{~nm}$ which was also measured at wet conditions ( $\mathrm{RH} \sim 80 \%$ ). Therefore, in order to properly compare the in situ measurements to the HSRL-2 measurements (and retrievals), it was necessary to adjust the dry in situ measurements to account for hygroscopic effects at the ambient RH.

Most ambient aerosol particles experience hygroscopic growth as the ambient RH increases. As the particle grows, the complex refractive index of the particle also changes.

The growth of a particle due to water uptake is described by the hygroscopic growth factor, $g\left(\mathrm{RH}, \mathrm{D}_{\mathrm{dry}}\right)$, which is defined as the ratio of the diameter of the particle at a certain $\mathrm{RH}, \mathrm{D}_{\mathrm{amb}}$, to its dry diameter, $\mathrm{D}_{\mathrm{dry}}$ :

$g\left(\mathrm{RH}, \mathrm{D}_{\mathrm{dry}}\right)=\frac{D_{\mathrm{amb}}(\mathrm{RH})}{D_{\mathrm{dry}}}$

As the particle grows due to water uptake, $m_{a m b}$ decreases and can be calculated by volume weighting the dry particle's refractive index $\mathrm{m}_{\mathrm{dry}}$ with the refractive index of water $\left(\mathrm{m}_{\mathrm{H}_{2} \mathrm{O}}=1.333 \pm 0 i\right.$, Hale and Querry (1973)) following:

$m_{\mathrm{amb}}=\frac{m_{\mathrm{dry}}+m_{\mathrm{H}_{2} \mathrm{O}}\left(g^{3}-1\right)}{g^{3}}$

The volume weighted mixing rule assumes the aerosols are homogeneously mixed as they undergo humidification.

For spherical particles, optical properties like scattering and absorption coefficients can be calculated with Mie theory if the size distribution and the complex refractive index $(m)$ of the aerosol particles are known. In this study we have in situ measurements of scattering and absorption coefficients and size distributions at dry conditions, but the $m_{d r y}$ values are unknown.

Once $m_{d r y}$ is determined, it is possible to use it with its respective size distribution in a hygroscopic growth model to reproduce the scattering coefficient measured at ambient conditions. In this process we are able to infer the effective hygroscopic growth factor, $\bar{g}$.

While $g\left(\mathrm{RH}, \mathrm{D}_{\mathrm{dry}}\right)$ can be measured with a tandem differential mobility analyzer (TDMA, Rader and McMurry (1986)), that instrument was not available during DAQ 2013. Therefore, in this study, the hygroscopic growth factor is assumed to be 
Atmos. Chem. Phys. Discuss., doi:10.5194/acp-2016-380, 2016

Atmospheric

Chemistry

Published: 17 May 2016

(c) Author(s) 2016. CC-BY 3.0 License.

$\frac{\text { and Physics }}{\text { Discussions }}$

(c) (i)

diameter-independent. For this reason we refer to it as an effective hygroscopic growth factor $\bar{g}$. Under this assumption the entire size distribution shifts to larger diameters by a factor of $\bar{g}$ when the hygroscopic correction is applied.

This methodology was developed based on Zieger et al. (2010). Zieger et al. (2010) also use the concept of effective growth factor, although in their study it is called apparent growth factor. In their study a fixed pair of complex refractive index is

5 assumed for all their measurements instead of being determined.

In the following subsections we describe how profiles of $m_{d r y}, m_{a m b}$ and $\bar{g}$ are retrieved from the in situ measurements.

\subsection{Data selection}

In order to directly compare the vertical profiles of HSRL-2 measurements and retrievals to in situ measurements, only the data obtained within a $10 \mathrm{~km}$ radius from the spiral center and 30 minutes from each other were considered. The spirals diameters were approximately $6 \mathrm{~km}$ in California and $8-10 \mathrm{~km}$ in Texas.

The vertical profiles of in situ measurements were obtained while the P-3B aircraft profiled the atmosphere in a series of ascending/descending spirals. Therefore, the vertical resolution of the in situ measurements varied with the ascent/descent rate. On average, the vertical resolution for the in situ profiles was about $5 \mathrm{~m}$. For this study, in order to standardize the vertical resolution of the in situ measurements, all profiles were interpolated to match the HSRL-2 $15 \mathrm{~m}$ vertical resolution using a smoothing spline. For the comparison with the HSRL-2 microphysical retrievals (Section 6), the in situ measurements were further reduced by applying a moving average and undersampling the in situ profiles in order to match the retrievals vertical resolution, i.e. $75 \mathrm{~m}$ for DAQ CA and $150 \mathrm{~m}$ for DAQ TX.

The HSRL-2 microphysical retrieval algorithm (Müller et al., 2014) is based on Mie theory (Mie, 1908) which describes the scattering of light by spherical particles. Therefore, the HSRL-2 dataset was further screened for data corresponding to high aerosol depolarization ratio at $532 \mathrm{~nm}\left(\delta_{532}\right)$ to avoid signals originated from non-spherical particles. Only measurements with $\delta_{532}<5 \%$ were considered.

Most of the data used in this study are publicly available in the DAQ website: http://www-air.larc.nasa.gov/missions/ discover-aq/discover-aq.html or using data doi: 10.5067/Aircraft/DISCOVER-AQ/Aerosol-TraceGas.

\subsection{Part I: Retrieving dry complex refractive index $\left(\mathbf{m}_{d r y}\right)$ from optical in situ measurements}

In the upper part of Figure 2 a block diagram summarizes the iterative algorithm used to retrieve $\mathrm{m}_{d r y}$ using the dry in situ data. The blue terms highlight the portions of the algorithm that use the in situ measurements. The profiles shown at the bottom of Figure 2 exemplify one of the many spirals obtained during DAQ TX. This particular spiral was performed over Channel View, in the Houston area, on September 11 ${ }^{\text {th }}, 2013$ between 21:06 - 21:15 UTC.

The calculation of scattering and absorption coefficients with Mie theory requires a size distribution and complex refractive index. Here, we use the dry scattering coefficients at $450 \mathrm{~nm}, 550 \mathrm{~nm}$, and $700 \mathrm{~nm}$ measured with the dry nephelometers, the dry absorption coefficients at $532 \mathrm{~nm}$ measured with the PSAP, and dry size distributions measured with the UHSAS in order to retrieve the vertical profiles of complex refractive index (at dry conditions, $\mathrm{m}_{d r y}$ ). $m$ is assumed to be wavelength-independent. 
Atmos. Chem. Phys. Discuss., doi:10.5194/acp-2016-380, 2016

Manuscript under review for journal Atmos. Chem. Phys.

For a given measured size distribution (dry), the scattering and absorption coefficients are calculated for a grid of real and imaginary parts of the refractive index, $m_{R}$ and $m_{i}$, respectively. In this grid, $m_{R}$ varies from 1.33 to 1.7 in 0.02 increments and $m_{i}$ varies from 0 to 0.03 in 0.001 increments. Assuming a wavelength-independent refractive index, the algorithm searches for the combination(s) of $m_{d r y, R}$ and $m_{d r y, i}$ that, along with the measured size distribution in a Mie code (Bohren and Huffman, 1983), allows the reproduction of the scattering coefficient measured in situ (dry) within $20 \%$ and the absorption coefficient within $2 \mathrm{Mm}^{-1}$. The final pairs of $m_{d r y, R}$ and $m_{d r y, i}$ are obtained by averaging all solutions that met the accuracy constraint.

In the bottom part of Figure 2 the black profiles are the measurements obtained with the nephelometer and the PSAP onboard the P-3B. The red profiles were calculated using the UHSAS size distribution and $\mathrm{m}_{d r y}$ (see Figure 3 ). The good agreement between the measured and calculated profiles of scattering and absorption in this figure originates from the strict constraint imposed by the algorithm, but it also demonstrates the consistency among the scattering, absorption, and size distribution measurements obtained with the various in situ instruments (Ziemba et al., 2013).

\subsection{Part II: Retrieving effective growth factors $(\bar{g})$ and complex refractive index corrected for ambient $\left.\mathbf{R H}_{(\mathrm{m}} \mathrm{m}_{a \mathrm{~m}}\right)$}

In this step the algorithm iterates over $\bar{g}$ values that range from 1 to 2 in 0.01 increments to correct the dry size distributions and the dry refractive index (as in Equations 3 and 4) that are used in a Mie code to calculate $\sigma_{\text {scat }, a m b}^{550 n m}$. The final $\bar{g}$ value is the one that allows the recalculation of $\sigma_{\text {scat }, a m b}^{550 \mathrm{~nm}}$ within $1 \%$ of the measured value.

Figure 3 shows the block diagram depicting the algorithm just described. The profiles at the bottom of this figure show the comparison between the measured scattering coefficient at $550 \mathrm{~nm}$, corrected for the ambient relative humidity as described by Ziemba et al. (2013), and the reconstructed profile calculated with this methodology. It also shows the profiles of the retrieved $\bar{g}, m_{d r y}$ (retrieved in Part I), and $m_{a m b}$.

20 More discussion on $\bar{g}$ can be found in Appendix A1.

\subsection{Part III: Closure study: Optical properties evaluation}

As described in Section 4, ambient extinction coefficients at $532 \mathrm{~nm}\left(\alpha_{532}\right)$ were computed from independent in situ measurements of scattering and absorption. Once the in situ size distributions are adjusted to account for hygroscopic effects, they can be used with $m_{a m b}$ in a Mie code in order to compute optical properties, such as extinction and backscatter coefficients. The comparison between the measured (in situ) and the calculated in situ ambient extinction coefficients at $532 \mathrm{~nm}$ showed excellent agreement with biases smaller than $1 \%$ for both DAQ CA and TX datasets (not shown), which should be expected given the strict constraint imposed for the retrieval of $\bar{g}$.

In addition to $\alpha_{532}$, the extinction coefficient at $355 \mathrm{~nm}\left(\alpha_{355}\right)$, and the backscatter coefficients at 355, 532, and 1064 nm $\left(\beta_{355}, \beta_{532}\right.$, and $\beta_{1064}$, respectively) were also computed with the adjusted in situ measurements. This $3 \beta+2 \alpha$ set calculated with the adjusted in situ measurements was then compared to the $3 \beta+2 \alpha$ set measured with the HSRL-2. 
Atmos. Chem. Phys. Discuss., doi:10.5194/acp-2016-380, 2016

Atmospheric

Chemistry

Published: 17 May 2016

(c) Author(s) 2016. CC-BY 3.0 License.

and Physics

Discussions

(c) (i)

\section{Results}

\subsection{Microphysical properties: Effective radius, and number, surface-area, and volume concentrations for the fine mode}

A total of 172 sets of coincident profiles (i.e. in situ and HSRL-2) were considered for the analysis of the microphysical

5 properties: 95 from DAQ TX and 77 from DAQ CA. Out of those, 108 profiles had valid data points for both HSRL-2 retrievals and adjusted in situ measurements: 76 from DAQ TX (630 data points) and 32 from DAQ CA (126 data points).

During DAQ CA the shallow boundary layers, commonly observed during the wintertime in the San Joaquin Valley, limited the number of measurements available for comparison. As previously mentioned, the HSRL-2 data were screened to ensure that the data used in the analyses corresponded to low depolarization ratio cases (i.e. $\delta_{532}<5 \%$ ). During DAQ CA out of the 70 valid HSRL-2 microphysical retrievals profiles, i.e. that had retrievals for more than half a profile (considering a full profile $\sim 2.5 \mathrm{~km}$ ), $49 \%$ had more than half of the profile screened out due to the presence of non-spherical particles. During DAQ TX, the incidence was only $8 \%$ for valid profiles (full profile $\sim 6 \mathrm{~km}$ ).

Despite the data losses experienced with the DAQ CA dataset, this study provides the most comprehensive evaluation of aerosol microphysical retrievals obtained from a multiwavelength lidar system (i.e. $3 \beta+2 \alpha$ ) to date. So far, efforts for a large scale evaluation of such retrievals have been limited to a few case studies at best. In this study we were able to evaluate the retrievals obtained from approximately 756 sets of $3 \beta+2 \alpha$.

The lidar inversion algorithm allows for the separation of the microphysical retrievals into fine and coarse mode. The fine mode definition for the lidar retrievals matches the range of particle sizes measured with the UHSAS (i.e. $D_{\max }=1 \mu$ m, before hygroscopic correction). Therefore, the comparisons between HSRL-2 retrievals and the adjusted in situ measurements of size parameters were performed for the fine mode retrievals only.

A few examples of profile-to-profile comparison from DAQ TX cases are presented in Figure 4. The error bars represent the HSRL-2 retrieval uncertainties, as described in Section 3.1. The error bars for the in situ measurements would have to account for the measurement errors and the potential uncertainties associated with the methodology used to calculate $\bar{g}$, which have not yet been quantified, and therefore are not displayed. Nevertheless, in this figure one can see how well the HSRL-2 retrievals compare with the in situ measurements, particularly in reproducing the finer structure of the vertical profile of surface-area and volume concentrations.

Figure 5 shows the comparison of all coincident points obtained with the HSRL-2 and the in situ instruments during DAQ CA and TX. Figure 6 shows the statistics of those same points in terms of the distribution of the relative biases (in \%) between HSRL-2 retrievals and adjusted in situ measuremets with respect to the average results between in situ and HSRL-2. The median biases in California and Texas, respectively, were: $47 \%$ and $33 \%$ for number concentration, $25 \%$ and $15 \%$ for surfacearea concentration, $3 \%$ and $7 \%$ for volume concentration, and $-25 \%$ and $-7 \%$ for effective radius.

In order to assess the effects of the hygroscopic adjustment in the comparison between in situ measurements and HSRL-2 retrievals of size parameters, the same analysis was performed using the dry in situ data. The results are also shown in Figure 6 , in lighter colors, indicating an increase in bias if the humidification effects are ignored. 
Atmos. Chem. Phys. Discuss., doi:10.5194/acp-2016-380, 2016

The uncertainties associated with the retrieval of the microphysics parameters from HSRL-2 data are currently being assessed. Preliminary results from sensitive studies performed with simulated data have shown that for $80 \%$ of the simulations the retrieval bias is smaller than $50 \%$ for effective radii. Similarly, for number, surface-area, and volume concentrations, the retrieval bias is better than $50 \%$ for $40 \%$ to $60 \%, 90 \%$ to $100 \%$, and $60 \%$ to $80 \%$ of the simulations, respectively.

In comparison, in this study the biases in effective radii, and number, surface-area, and volume concentrations were smaller than $50 \%$ for $96 \%, 56 \%, 81 \%$, and $86 \%$ of the 756 cases analyzed, demonstrating that the HSRL-2 retrievals of aerosol size parameters agree very well with the in situ measurements once hygroscopic growth is taken into account (see Table 2).

\subsection{Optical properties: extinction and backscatter coefficients (closure study)}

For the analysis of optical properties we were able to use more data points due to the higher resolution (in altitude) of the HSRL-2 optical data products in comparison to the microphysical retrievals.

The results of this closure study are presented in Figure 7. The results for California are displayed on the top row and the results for Texas on the bottom row. The red dashed lines in Figure 7 correspond to bisector linear regressions and their fit parameters are listed on the first two columns of Table 3. In general, we observe that the measured and the calculated $3 \beta+2 \alpha$ are well correlated. However the measured $3 \beta+2 \alpha$ are usually larger than those calculated from the in situ measurements, and the trend is accentuated in the Texas dataset. It is interesting to note that in the Texas dataset better agreement was observed for the extinction coefficients than for the backscatter.

The extinction measurements obtained with the HSRL-2 during DAQ CA and TX were used to calculate aerosol optical thickness (AOT) and compared to AERONET - DRAGON (Distributed Regional Aerosol Gridded Observation Network) measurements obtained within $2.5 \mathrm{~km}$ and 10 minutes of each other. Excellent agreement was observed as can be seen in Figure 8.

One of the possible explanations for the systematic underestimation in the calculated in situ optical dataset is related to the potential difference between the aerosol size ranges measured in situ and those measured with the HSRL-2.

Unlike in situ instruments, a lidar system like HSRL-2, does not have a mechanical constraint limiting the size range and/or the number of particles being measured. The measurements obtained from a lidar system operating in the visible range, for instance, are mostly affected by aerosol particles with radii up to 50 times larger than the operating wavelength (Kovalev and Eichinger, 2004; Weitkamp, 2005).

In the evaluation of the HSRL-2 microphysical retrievals only the fine mode was considered, thus ensuring very similar aerosol size ranges for both datasets.

In the case of optical properties, Mamouri and Ansmann (2014) have demonstrated a method that allows for the separation of fine and coarse dust measurements using a polarization lidar. However in this study, the optical measurements obtained with the HSRL-2 were not separated into fine and coarse modes. Therefore, when larger aerosols are present, one can expect differences when optical properties measured for the total aerosol mode (fine+coarse) are compared to those calculated from measurements that are mostly only due to the fine mode of aerosols. 
Atmos. Chem. Phys. Discuss., doi:10.5194/acp-2016-380, 2016

Atmospheric

Manuscript under review for journal Atmos. Chem. Phys.

Chemistry

Published: 17 May 2016

(c) Author(s) 2016. CC-BY 3.0 License.

$\frac{\text { and Physics }}{\text { Discussions }}$

(c) (i)

We investigated the effect of including large particles in the analysis by rerunning the method described in Section 5 using, this time, the dry in situ size distributions obtained with the Laser Aerosol Spectrometer (LAS) which measures particles with sizes up to $7.5 \mu \mathrm{m}$ in diameter (note that during DAQ only particles smaller than $5 \mu \mathrm{m}$ in diameter were allowed into the aircraft instruments (McNaughton et al., 2007)).

5 LAS measurements were only available during DAQ CA, and the results of the comparison between the calculated (in situ) and measured optical properties are presented in the third column of Table 3.

It is unfortunate that the same test could not be performed with the DAQ TX dataset, which clearly showed poorer agreement between the HSRL-2 measurements of $3 \beta+2 \alpha$ and those derived from the adjusted in situ measurements. Nevertheless, the results from the reanalysis using LAS measurements from California show that, by including larger particles (i.e. D > $1 \mu \mathrm{m}$ ), the agreement between the calculated in situ optical properties and those measured with HSRL-2 improves. The bias was improved by $5 \%$, on average.

The most notable improvement was observed in the calculated backscatter coefficient at $1064 \mathrm{~nm}\left(\beta_{1064}\right)$ which improved by $17 \%$. The backscatter efficiency is a function of size parameter $x$, defined as $\pi D / \lambda$. For $x>2$ the backscatter efficiency is known to increase for low absorbing aerosols (Collis and Uthe, 1972; Solarz and Paisner, 1986). Since the aerosols observed during DAQ (CA and TX) were mostly non-absorbing, the underestimation of $\beta_{1064}$ when larger particles are neglected could be expected.

Figure 9 shows the statistics of the biases observed between the optical properties measured with the HSRL-2 and those calculated from in situ size distributions (adjusted to ambient RH). Similarly to the results from Figure 6, the relative biases of the $3 \beta+2 \alpha$ were calculated with respect to the average between the adjusted in situ measurements and the HSRL-2 measurements. In the x-axis, $1 \mathrm{a}$ and $1 \mathrm{~b}$ refer to the results from California obtained with the UHSAS and the LAS, respectively, and 2 refers to the results obtained in Texas with the UHSAS. The results obtained with the LAS instrument in California (light blue box) show the lowest median biases for most optical properties, compared to the results obtained both in California and Texas with the UHSAS, except for the backscatter coefficient at $355 \mathrm{~nm}$, which changed by less than $1 \%$.

In a comparison study between in situ, lidar, and MAX-DOAS (multi-axis differential optical absorption spectroscopy) measurements of ambient aerosol extinction coefficients Zieger et al. (2011) also observed that the remote sensing measurements were larger than those obtained in situ. The authors hypothesize that particle losses in the inlet system could have been one of the causes for the discrepancies observed. Kassianov et al. (2012) highlight the importance of sampling supermicron particles due to the potential of significant impact of supermicron aerosols in the calculation of aerosol radiative properties in areas where the relative contribution of the supermicron fraction is often overlooked.

\subsubsection{Effects of incomplete particle size distributions in the calculation of optical properties}

Figure 10A shows the average size distribution retrievals (in volume) from AERONET/DRAGON sunphotometers obtained during DAQ 2013. Figure 10B shows that the median aerosol optical depth (AOD) fine fraction (O'Neill et al., 2001) is smaller for Texas (0.73) than for California (0.79). The AOD fine fraction observed in Texas shows larger variability toward lower 
Atmos. Chem. Phys. Discuss., doi:10.5194/acp-2016-380, 2016

Manuscript under review for journal Atmos. Chem. Phys.

fractions, indicating that it is possible that undersampling of large particles might have been a factor in the discrepancies of measured and calculated $3 \beta+2 \alpha$.

In order to investigate how an imposed cut-off diameter can bias the in situ measurements, simulations were performed using theoretical bimodal size distributions for the calculation of the optical parameters. We used 4 distinct size distributions with varying sub- and super-micron fractions (Figure 11A). The bin sizes were $\operatorname{d} \log \mathrm{D}=0.05$ for $\mathrm{D}<1 \mu \mathrm{m}$ and $\operatorname{d} \log \mathrm{D}=0.1$ for $\mathrm{D}$ $\geq 1 \mu \mathrm{m}$. Each optical parameter was calculated with varying cut-off diameter (i.e. maximum limit for the size distribution) which varied from $11 \mathrm{~nm}$ to $21 \mu \mathrm{m}$ (complete size distribution) in 123 intervals, for a complex index of refraction $\left(\mathrm{m}_{R}=1.5\right.$, $\mathrm{m}_{i}=0.01$ ). Figure $11(\mathrm{~B}-\mathrm{F})$ shows how well the optical parameters are reproduced as the cut-off diameters $\mathrm{D}_{c u t}$ change.

The UHSAS instrument measures dry particles as large as $1 \mu \mathrm{m}$ in diameter. Taking the hygroscopic correction into account

( $\bar{g} \sim 1.2$ for DAQ), it is reasonable to assume that the upper diameter threshold becomes $\sim 1.2 \mu \mathrm{m}$. Table 4 summarizes the values from Figures $11 \mathrm{~B}-11 \mathrm{~F}$ at reference points $\mathrm{D}_{\text {cut }}=1.2,0.7$, and $0.4 \mu \mathrm{m}$.

By comparing the results of these simulations with the fit parameters presented in Table 3 ( $2^{\text {nd }}$ column, DAQ TX), two similar features can be observed: (1) the optical parameters measured at shorter wavelengths are better reproduced than those at longer wavelengths, which is consistent with the backscatter and extinction efficiencies being functions of the size parameter $x$ which relates the diameter of the particles measured with the wavelength used in the measurement. This feature seem to be more pronounced for the backscatter. (2) the extinction is better reproduced than the backscatter.

The results of these simulations are interesting due to the aforementioned similarities to the results obtained with the measurements, but are not conclusive. While some supermicron particle losses are to be expected due to the limitation of the UHSAS instrument, as was demonstrated with the California data, it is not possible to quantify from these results the effects of such losses in the underestimation observed in the calculation of the $3 \beta+2 \alpha$ dataset with the in situ measurements obtained in Texas.

\section{Discussion}

The main objective of this study, initially, was to compare effective radii, and aerosol number, surface-area, and volume concentrations obtained from the inversion of HSRL-2 measurements of backscatter and extinction to those obtained in situ.

In Section 6.1 we have shown that the HSRL-2 fine mode retrievals agree well with the in situ measurements once these are corrected for hygroscopic effects.

In the previous section we also calculated the $3 \beta+2 \alpha$ optical dataset using the adjusted in situ size parameters and compared them to the HSRL-2 measurements. Once the results showed that the HSRL-2 optical data measured in California was better reproduced with the in situ measurements than those measured in Texas (Figure 7), investigating the reason for this discrepancy became an additional objective in this study.

In order to properly and critically evaluate these results, one must keep in mind some of the limitations that are inherent in evaluation studies of this kind. An ideal study for the evaluation of retrieved products would require the knowledge of the 
Atmos. Chem. Phys. Discuss., doi:10.5194/acp-2016-380, 2016

Manuscript under review for journal Atmos. Chem. Phys.

"true state" of the system being analyzed, i.e. a set of error-free measurements against which the retrievals can be compared. However in reality all measurements are subject to errors and uncertainties.

For the evaluation of the HSRL-2 size parameter retrievals, direct in situ measurements of those same parameters were the best choice to be used as a reference. However the HSRL-2 and the in situ measurements were obtained from different aircraft. In order to compare those measurements it was necessary to set a colocation "window" within which the air mass analyzed is assumed to remain reasonably unchanged. In this study this window was set to measurements obtained within $10 \mathrm{~km}$ of the P-3B spiral center, and 30 minutes from each other.

Additionally, the in situ measurements were not obtained at ambient RH conditions like the HSRL-2 measurements, and aerosol particles are known to increase in size with water uptake. Hygroscopic corrections had to be estimated before the in situ measurements of size distributions could be considered a resonable reference.

In Appendix A we assess the effect of the diameter-independence assumption in the retrieval of the effective growth factors from the in situ measurements. In this evaluation we used synthetic data as the true state and the biases of the retrievals were assessed. The results indicated that that the hygroscopicity-corrected size parameters $\mathbf{S}_{a m b}, \mathbf{V}_{a m b}$, and $\mathbf{R}_{e f f_{a m b}}$ can be, on average, overestimated by $34 \%, 23 \%$, and $8 \%$, respectively (Table A2). These biases originate from the bias in the retrieval of $\bar{g}(\sim 10 \%)$ and based on the simulation results this overestimation seems to be systematic and insensitive to errors of up to $20 \%$.

In addition to the systematic errors originated from the retrieval of $\bar{g}$, we must also consider the potential sources of uncertainties for the in situ measurements that are used as inputs, such as the dry size distributions measured with either the UHSAS or the LAS, and the scattering coefficient at $550 \mathrm{~nm}$ at ambient RH.

Optical particle counters, like those used in this study, are known to undersize aerosol particles due to a bias between the refractive index of the material used for calibration and the true refractive index of the particles measured in the atmosphere, which is usually lower (Liu and Daum, 2000; Pinnick et al., 2000). This artifact, if not corrected, can introduce a bias of about $40 \%$ in total scattering closure studies as demonstrated by Kassianov et al. (2015). In Kassianov et al. (2015) the refractive index correction was obtained from chemical composition data. In this study we assume that most aerosols are composed of ammonium sulfate. This assumption has also been used in other studies (Brock et al., 2011; Ziemba et al., 2013; Beyersdorf et al., 2016). The uncertainty for particle diameters $<0.5 \mu \mathrm{m}$, assuming that the real $\mathrm{m}_{R}$ ranges between $1.43-1.56$ and $\mathrm{m}_{I}=0$, was found to be $8 \%$ in diameter for the ammonium sulfate calibration (Brock et al., 2011). Any uncertainty in the size distributions would propagate into the retrieval of $\bar{g}$, and consequently into the calculation of the in situ $\mathrm{S}_{a m b}, \mathrm{~V}_{a m b}$, and $\mathbf{R}_{e f f_{a m b}}$ and optical properties (i.e. $3 \beta+2 \alpha$ ).

\subsection{Aerosol composition and $\mathrm{RH}_{a m b}$ in TX:}

The hygroscopic behavior of aerosol particles is strongly dependent on their composition. In humid environments the phase of single salt particles, such as sulfates and chlorides, remain unchanged until $\mathrm{RH}_{a m b}$ reach the deliquescence $\mathrm{RH}$ (DRH). At this point those particles deliquesce rapidly to form a saturated solution droplet. This transition corresponds to an abrupt change in 
Atmos. Chem. Phys. Discuss., doi:10.5194/acp-2016-380, 2016

Atmospheric

Chemistry

Published: 17 May 2016

(c) Author(s) 2016. CC-BY 3.0 License.

and Physics

Discussions

(c) (i)

particle size at DRH, and the hygroscopic growth factor increases from 1 to 1.5, approximately (Gysel et al., 2002; Hu et al., 2010).

The hygroscopic characteristics of inorganic particles are well understood, however knowledge on the hygroscopic properties of organic particles still remains very limited (Kanakidou et al., 2005).

5 When inorganic particles like sulfates are mixed with water-soluble organic carbon (WSOC) particles, for instance, their hygroscopicity is known to change (Saxena et al., 1995). The change can be either positive, i.e. organics add to water absorption of inorganics, or negative, depending on how hydrophobic or hydrophilic the WSOC particles are (Sullivan and Weber, 2006). Pure solid ammonium sulfate particles, for instance, deliquesce at 80\% RH (Martin, 2000) but when mixed with organic particles its DRH is lowered (Smith et al., 2012).

Texas experienced high relative humidity during DAQ with values sometimes exceeding $80 \%$ (Figure 12C) and a brief analysis of the aerosol composition measurements obtained with a Particle-Into-Liquid-Sampler (PILS - flown onboard the $\mathrm{P}-3 \mathrm{~B}$ ) revealed that WSOC and sulfates were the most abundant aerosol components (in mass) (Figure 12B).

Therefore it is likely that, in some cases, the aerosols observed in Texas displayed a complex hygroscopic behavior that could not be properly parameterized by the $\gamma$ power-law parameterization (see Section 4). In fact, Brock et al. (2016) discusses the effectiveness of the $\gamma$ parameterization in replicating observations obtained during another field campaign, also in Texas, that was being conducted at the same time as DAQ TX. In their contribution they present an alternative parameterization based on $\kappa$-Köhler theory that better describes their measurements, which included aerosol extinction at $532 \mathrm{~nm}$ at three RH (15\%, $70 \%$, and $90 \%$ ). They found that the $\gamma$ parameterization overestimated the actual hygroscopic growth by $10 \%$ at $60 \%$ RH, and $8 \%$ at $70 \%$ RH.

In contrast to sulfates, nitrate particles do not experience an abrupt change in size at DRH. Instead, the size of nitrate particles increases smoothly with RH (Gibson et al., 2006; Hu et al., 2011), which makes a single-parameter fitting like the $\gamma$ parameterization more likely to succeed in predicting the $\sigma_{\text {scat,amb }}^{550 \mathrm{~nm}}$ at intermediate RH values.

In California, the aerosol composition analysis revealed that nitrates were the most abundant aerosol type (Figure 12A) which is consistent with other studies conducted in San Joaquin Valley, Callifornia during wintertime (Watson and Chow, 2002; Lurmann et al., 2006; Pusede et al., 2016). The RH values observed in California were mostly below 70\% (Figure 12C).

With this analysis it is possible to hypothesize that the differences in composition and RH between California and Texas might have contributed, even if by a small percentage, to the overall bias observed in the $3 \beta+2 \alpha$ comparison between the HSRL-2 measurements and those calculated from the adjusted in situ measurements. The effects of applying a different parameterization for the calculation of $\sigma_{\text {scat,amb }}^{550 \mathrm{~nm}}$ with the Texas dataset should be further investigated.

\section{Summary and conclusions}

The main objective of this study was to analyze the retrievals of effective radii, and number, surface-area, and volume concentrations for the fine mode of aerosols obtained from the HSRL-2 optical measurements by comparing those retrievals to vertically resolved in situ measurements obtained during DAQ field campaign in 2013. 
Atmos. Chem. Phys. Discuss., doi:10.5194/acp-2016-380, 2016

Manuscript under review for journal Atmos. Chem. Phys.

The HSRL-2 retrievals of the aerosol size parameters for the fine mode agreed very well with the in situ measurements once the latter was corrected for hygroscopicity, especially when compared to a preliminary assessment of the systematic errors in the retrieval of microphysical properties from HSRL-2 measurements. The vertical structure of the size parameters retrieved from the HSRL-2 measurements correlates very well with those observed from the in situ measurements, especially for surface-area and volume concentrations. The biases between HSRL-2 retrievals and in situ measurements in California and Texas, respectively, were $25 \%$ and $15 \%$ for surface-area concentrations, and $3 \%$ and $7 \%$ for volume concentration.

This study was, so far, the most extensive evaluation of microphysical retrievals from inversion of multiwavelength lidar measurements. In this study we were able to evaluate the retrievals obtained from approximately 756 sets of $3 \beta+2 \alpha(100+$ profiles).

Closure studies were performed to compare extinction and backscatter coefficients $(3 \beta+2 \alpha)$ measured with HSRL-2 to those calculated with Mie theory after refractive indices (at ambient RH) and hygroscopic corrections were estimated from in situ measurements and applied to the dry size distributions. A general trend is observed, in which the calculated parameters are well correlated to the measurements, but the former are underestimated with respect to the measurements. In particular, the trend was accentuated with the data obtained in Texas.

With the measurements obtained in California, the extinction and backscatter coefficients measured with the HSRL-2 were well reproduced by the in situ measurements. By addressing the potential loss of larger particles due to instrument limitation - by repeating the analysis using measurements from a particle sizer capable of measuring supermicron particles (LAS) - the agreement between measured and calculated extinction and backscatter was further improved. Due to lack of LAS measurements during DAQ TX, the same effect could not be assessed using measurements, but a simulation study demonstrated the potential for the supermicron particle losses to partly explain the observed discrepancies.

It is speculated, based on simulations and available data, that a combination of supermicron particle losses, differences in aerosol composition and ambient RH between wintertime in California and summertime in Texas, and potential problems with the hygroscopic parameterization used with the in situ data played a significant role in the observed discrepancies. Unfortunately, it was not possible to estimate by how much.

Regardless of the number of uncertainties that can affect studies like this one, we have demonstrated that the HSRL-2 retrievals of fine mode aerosol size parameters are well correlated to in situ measurements. Further work is still necessary in order to more effectively quantify the net effects of such uncertainties in comparison studies of this kind.

Other retrieval schemes are currently in development and being tested with the same $3 \beta+2 \alpha$ data that were used in this study (i.e. obtained with the HSRL-2 during DAQ 2013), namely the optimal estimation and the "arrange-and-average" technique 30 (Chemyakin et al., 2014). In future contributions we expect to be able to compare the retrievals obtained with all three schemes, which will help us to better understand the robustness and also the limitations of multiwavelength lidar retrievals. 
Atmos. Chem. Phys. Discuss., doi:10.5194/acp-2016-380, 2016

Manuscript under review for journal Atmos. Chem. Phys.

\section{Appendix A: Evaluation of in situ retrieval algorithm}

\section{A1 Effective growth factors}

The relationship between hygroscopic growth factor and $\mathrm{RH}$ for a given aerosol type can be parameterized in a good approximation by a single parameter equation (Petters and Kreidenweis, 2007):

$5 g\left(a_{w}\right)=\left(1+\kappa \frac{a_{w}}{1-a_{w}}\right)^{1 / 3}$

where $a_{w}$ is the water activity which can be replaced by the RH in cases where the Kelvin effect is negligible. In this study we can make this assumption, as it is a reasonable for aerosol particles with diameters larger than $50 \mathrm{~nm}$ (Zhang and Wexler, 2002). $\kappa$ is a hygroscopicity parameter that takes all the aerosol solute properties into account. For most atmospheric particulate matter, $\kappa$ ranges between 0.1 and 0.8 (Petters and Kreidenweis, 2007). The higher the $\kappa$, the more hygroscopic the aerosol is. Over the continent $\kappa$ values are mostly in the range of 0.1-0.4. Values ranging between 0.4-0.6 are typical of mixes containing sea spray aerosols and other less hygroscopic aerosol (Pringle et al., 2010).

Figure A1 shows the relationship between all $\bar{g}$ values retrieved from the in situ measurements and the measured RH as density scatter plots. The isolines plotted over the data represent a few $\kappa$ values (see Equation A1). In Figure A1 one can observe that the retrieved values of $\bar{g}$ fall within the isolines of $\kappa$ values that are commonly observed for aerosol particles (Petters and Kreidenweis, 2007; Pringle et al., 2010) .

While the determination and validation of aerosol hygroscopicity parameters were not the focus of this study, these results are encouraging as they suggest that this methodology allows for the estimation of reasonable growth factors. For reference, the hygroscopic growth factor for a dry diameter of $100 \mathrm{~nm}$ for ammonium nitrate $\left(\mathrm{NH}_{4} \mathrm{NO}_{3}\right)$ at $60 \% \mathrm{RH}$ is about $1.3(\mathrm{Hu}$ et al., 2011) and for ammonium sulfate $\left(\mathrm{NH}_{4} \mathrm{SO}_{4}\right)$ at $85 \% \mathrm{RH}$ is about 1.5 (Tang et al., 1978). However, the growth factor for mixtures of ammonium sulfate and organics are known to be smaller (Cruz et al., 2000). In particular, for mixtures containing more organics than ammonium sulfate this value can be as low as 1.17 (at $85 \% \mathrm{RH}$ ). The values obtained for $\bar{g}$ averaged 1.15 \pm 0.11 for California and $1.21 \pm 0.10$ for Texas.

\section{A2 Simulations}

The effect of the diameter-independence assumption in the retrieval of the effective growth factors from the in situ measurements is assessed using simulated data.

Combinations of size distribution, complex index of refraction, and hygroscopic growth factors were generated in order to obtain sets of "true states" using a forward model based on the methodology described in Section 5 and Mie theory. The retrieval methodology described in sections 5.2 and 5.3 was then performed with these simulated datasets in order to quantify the performance of the algorithm in reproducing the said true states. The parameters that describe the sample particles were chosen randomly from a range of values so that the distribution of Ångström exponents between $355 \mathrm{~nm}$ and $532 \mathrm{~nm}$ that were measured with HSRL-2 during DAQ CA and TX could be reproduced (Figure A2). 
Atmos. Chem. Phys. Discuss., doi:10.5194/acp-2016-380, 2016

Manuscript under review for journal Atmos. Chem. Phys.

The number size distributions used in the simulations were bimodal lognormal distributions. All size distributions were normalized to 1 for simplicity. Initially, the particles were simulated at dry conditions (i.e. low relative humidity). Each mode was assigned a number concentration $N_{i}$, a mean diameter $D_{m, i}$, a geometic standard deviation $\sigma_{i}$, and a complex index of refraction $m_{i}=m_{R, i}+i m_{I, i}$, where the subscript $i$ denotes the size distribution mode. The diameter space utilized in the calculations ranged from $0.01 \mu \mathrm{m}$ to $11.5 \mu \mathrm{m}$.

In the forward calculation an effective complex index of refraction was used, which was computed using the volume mixing rule.

In order to take water uptake into account in the forward model, a similar hygroscopic model as the one described in Section 5 was used. The difference here was that the assumption of a diameter-independent hygroscopic factor was not used. Instead, similarly to the other parameters, the modal hygroscopic growth factors were also randomly chosen for each mode of each sample.

The range of parameters for the bimodal size distributions used in the simulations are listed on Table A1. 451 samples were generated for California and 242 for Texas.

The same set of variables utilized in Sections 5.2 and 5.3 was calculated for each sample. The dataset consisted of number size distribution (low RH), scattering coefficients at $450 \mathrm{~nm}, 550 \mathrm{~nm}$, and $700 \mathrm{~nm}$ (low RH), absorption coeffcient at $532 \mathrm{~nm}$ (low RH), and scattering coefficient at $550 \mathrm{~nm}$ (ambient RH).

For each sample (i.e. California and Texas) two cases were evaluated. In the first case the measurements are assumed to be noise-free in order to quantify the biases caused solely by the retrieval algorithm. In the second case it was assumed up to $20 \%$ random error for the size distributions, up to $10 \%$ random error for the dry optical data, and up to $20 \%$ random error for the ambient scattering.

The correlation coefficient, the root mean square error (RMSE), and the bias were used as metric in this evaluation, and the results are presented in Table A2. In the case with added noise, the algorithm was run 10 times in order to evaluate its robustness when dealing with noisy data. The errors presented in this scenario are the standard deviation of each parameter (i.e. R, bias, RMSE) obtained from those 10 runs.

This analysis (see Table A2) shows that the bias and RMSE are consistent for both samples. It also shows only a slight increase in RMSE and bias between the noise-free and the noise-added scenarios for the parameters calculated at ambient RH. This small increase is most likely due to the hard constraint imposed in the second part of the in situ retrieval algorithm, in which $\bar{g}$ is calculated, where it requires the calculated ambient scattering coefficient at $550 \mathrm{~nm}$ to agree with the measurements within $1 \%$.

The largest differences between the noise-free and the noisy cases were observed in the retrieval of the dry complex index of refraction $m I_{d r y}$. The largest biases are also observed in the retrieval of $m_{I}$. The retrieval of absorption coefficient and other parameters closely associated with it, such as $m I$, is known to be a challenging one. For instance, Böckmann et al. (2005) notes that with respect to the inversion of optical data from lidar measurements for the retrieval of microphysical properties, $m_{I}$ has a large influence on the degree of ill-posedness of the inversion problem. They report errors of up to $35 \%$ in the retrieval of $m_{I}$ for a noise level of $10 \%$ for the $3 \beta+2 \alpha$ setting. 
Atmos. Chem. Phys. Discuss., doi:10.5194/acp-2016-380, 2016

Manuscript under review for journal Atmos. Chem. Phys.

Published: 17 May 2016

(c) Author(s) 2016. CC-BY 3.0 License.

(c) (i)
Atmospheric

Chemistry

and Physics

Discussions

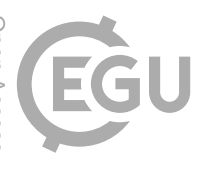

The results also indicate that that the hygroscopicity-corrected size parameters $\mathrm{S}_{a m b}, \mathrm{~V}_{a m b}$, and $\mathrm{R}_{e f f_{a m b}}$ can be, on average, overestimated by $34 \%, 23 \%$, and $8 \%$, respectively (Table A2). These biases originate from the bias in the retrieval of $\bar{g}(\sim$ $10 \%$ ) and based on the simulation results this overestimation seems to be systematic and insensitive to errors of up to $20 \%$. Some of the possible sources for the bias in the retrieval of $\bar{g}$ in this simulation study may be due to an incomplete and/or 5 oversimplified hygroscopic model both in the retrieval and in the forward model including the assumption of a diameterindependent hygroscopic growth factor, for instance.

The assumption of a wavelength-independent refractive index and the volume mixing rule were both applied in the calculation of the synthetic data and in the retrieval algorithm, thus masking any retrieval bias that could have originated from those assumptions not being valid in reality. However when real measurements are used instead, any assumption in the retrieval algorithm that does not match what it is observed in nature is likely to affect the quality of the retrieved products. And those biases are quite difficult to assess.

Acknowledgements. This research was supported by an appointment to the NASA Postdoctoral Program at the NASA Langley Research Center, administered by Oak Ridge Associated Universities (now administered by Universities Space Research Association) under contract with NASA. The authors would like to thank the flight crew from both NASA B200 and P-3B, and the team members of the NASA

15 Langley Aerosol Research Group Experiment (LARGE) and others who contributed to the data processing and archival process for the DISCOVER-AQ data. The authors would also like to thank Amy Jo Scarino for her contribution with the AOT comparison between HSRL-2 and AERONET measurements during DAQ CA and TX. 
Atmos. Chem. Phys. Discuss., doi:10.5194/acp-2016-380, 2016

Atmospheric

Chemistry

Published: 17 May 2016

(c) Author(s) 2016. CC-BY 3.0 License.

and Physics

Discussions

(c) (i)

\section{References}

Alados-Arboledas, L., Müller, D., Guerrero-Rascado, J. L., Navas-Guzmán, F., Pérez-Ramírez, D., and Olmo, F. J.: Optical and microphysical properties of fresh biomass burning aerosol retrieved by Raman lidar, and star- and sun-photometry, Geophys. Res. Lett., 38, doi:10.1029/2010GL045999, 2011.

5 Ames, R. B., Hand, J. L., Kreidenweis, S. M., Day, D. E., and Malm, W. C.: Optical Measurements of Aerosol Size Distributions in Great Smoky Mountains National Park: Dry Aerosol Characterization, Journal of the Air \& Waste Management Association, 50, 665-676, doi:10.1080/10473289.2000.10464128, 2000.

Anderson, T. L. and Ogren, J. A.: Determining Aerosol Radiative Properties Using the TSI 3563 Integrating Nephelometer, Aerosol Science and Technology, 29, 57-69, doi:10.1080/02786829808965551, 1998.

Balis, D., Giannakaki, E., Müller, D., Amiridis, V., Kelektsoglou, K., Rapsomanikis, S., and Bais, A.: Estimation of the microphysical aerosol properties over Thessaloniki, Greece, during SCOUT-O 3 campaign with the synergy of Raman lidar and Sun photometer data, J. Geophys. Res, 115, doi:10.1029/2009JD013088, 2010.

Baumgardner, D., Brenguier, J., Bucholtz, A., Coe, H., DeMott, P., Garrett, T., Gayet, J., Hermann, M., Heymsfield, A., Korolev, A., Krämer, M., Petzold, A., Strapp, W., Pilewskie, P., Taylor, J., Twohy, C., Wendisch, M., Bachalo, W., and Chuang, P.: Airborne instruments to measure atmospheric aerosol particles, clouds and radiation: A cook's tour of mature and emerging technology, Atmospheric Research, 102, 10 - 29, doi:10.1016/j.atmosres.2011.06.021, 2011.

Berg, L. K., Fast, J. D., Barnard, J. C., Burton, S. P., Cairns, B., Chand, D., Comstock, J. M., Dunagan, S., Ferrare, R. A., Flynn, C. J., Hair, J. W., Hostetler, C. A., Hubbe, J., Jefferson, A., Johnson, R., Kassianov, E. I., Kluzek, C. D., Kollias, P., Lamer, K., Lantz, K., Mei, F., Miller, M. A., Michalsky, J., Ortega, I., Pekour, M., Rogers, R. R., Russell, P. B., Redemann, J., Sedlacek, A. J., Segal-Rosenheimer, M., Schmid, B., Shilling, J. E., Shinozuka, Y., Springston, S. R., Tomlinson, J. M., Tyrrell, M., Wilson, J. M., Volkamer, R., Zelenyuk, A., and Berkowitz, C. M.: The Two-Column Aerosol Project: Phase I-Overview and impact of elevated aerosol layers on aerosol optical depth, Journal of Geophysical Research: Atmospheres, 121, 336-361, doi:10.1002/2015JD023848, 2016.

Beyersdorf, A. J., Ziemba, L. D., Chen, G., Corr, C. A., Crawford, J. H., Diskin, G. S., Moore, R. H., Thornhill, K. L., Winstead, E. L., and Anderson, B. E.: The impacts of aerosol loading, composition, and water uptake on aerosol extinction variability in the Baltimoreâ€"Washington, D.C. region, Atmospheric Chemistry and Physics, 16, 1003-1015, doi:10.5194/acp-16-1003-2016, 2016.

Böckmann, C., Mironova, I., and Müller, D.: Microphysical aerosol parameters from multiwavelength lidar, J. Opt. Soc. Am. A, 22, 518-528, doi:10.1364/JOSAA.22.000518, 2005.

Bohren, C. F. and Huffman, D. R.: Absorption and scattering of light by small particles, Wiley Science Paperback Series, Wiley, 1983.

Brock, C. A., Cozic, J., Bahreini, R., Froyd, K. D., Middlebrook, A. M., McComiskey, A., Brioude, J., Cooper, O. R., Stohl, A., Aikin, K. C., de Gouw, J. A., Fahey, D. W., Ferrare, R. A., Gao, R.-S., Gore, W., Holloway, J. S., Hübler, G., Jefferson, A., Lack, D. A., Lance, S., Moore, R. H., Murphy, D. M., Nenes, A., Novelli, P. C., Nowak, J. B., Ogren, J. A., Peischl, J., Pierce, R. B., Pilewskie, P., Quinn, P. K., Ryerson, T. B., Schmidt, K. S., Schwarz, J. P., Sodemann, H., Spackman, J. R., Stark, H., Thomson, D. S., Thornberry, T., Veres, P., Watts, L. A., Warneke, C., and Wollny, A. G.: Characteristics, sources, and transport of aerosols measured in spring 2008 during the aerosol, radiation, and cloud processes affecting Arctic Climate (ARCPAC) Project, Atmospheric Chemistry and Physics, 11, 2423-2453, doi:10.5194/acp-11-2423-2011, 2011.

Brock, C. A., Wagner, N. L., Anderson, B. E., Attwood, A. R., Beyersdorf, A., Campuzano-Jost, P., Carlton, A. G., Day, D. A., Diskin, G. S., Gordon, T. D., Jimenez, J. L., Lack, D. A., Liao, J., Markovic, M. Z., Middlebrook, A. M., Ng, N. L., Perring, A. E., Richardson, M. S., 
Atmos. Chem. Phys. Discuss., doi:10.5194/acp-2016-380, 2016

Atmospheric

Chemistry

Manuscript under review for journal Atmos. Chem. Phys.

Published: 17 May 2016

(c) Author(s) 2016. CC-BY 3.0 License.

and Physics

Discussions

(c) $\underset{\mathrm{Br}}{\mathrm{i}}$

Schwarz, J. P., Washenfelder, R. A., Welti, A., Xu, L., Ziemba, L. D., and Murphy, D. M.: Aerosol optical properties in the southeastern United States in summer â€“ PartÂ 1: Hygroscopic growth, Atmospheric Chemistry and Physics, 16, 4987-5007, doi:10.5194/acp-164987-2016, 2016.

Carrico, C. M., Kus, P., Rood, M. J., Quinn, P. K., and Bates, T. S.: Mixtures of pollution, dust, sea salt, and volcanic aerosol during ACE-Asia:

Radiative properties as a function of relative humidity, Journal of Geophysical Research: Atmospheres, 108, doi:10.1029/2003JD003405, 2003.

Chemyakin, E., Müller, D., Burton, S. P., Kolgotin, A., Hostetler, C. A., and Ferrare, R. A.: Arrange and average algorithm for the retrieval of aerosol parameters from multiwavelength high-spectral-resolution lidar/Raman lidar data, Appl. Opt., 53, 7252-7266, doi:10.1364/AO.53.007252, 2014.

Clarke, A. D., Howell, S., Quinn, P. K., Bates, T. S., Ogren, J. A., Andrews, E., Jefferson, A., Massling, A., Mayol-Bracero, O., Maring, H., Savoie, D., and Cass, G.: INDOEX aerosol: A comparison and summary of chemical, microphysical, and optical properties observed from land, ship, and aircraft, Journal of Geophysical Research: Atmospheres, 107, INX2 32-1-INX2 32-32, doi:10.1029/2001JD000572, 2002.

Collis, R. and Uthe, E.: Mie scattering techniques for air pollution measurement with lasers, Opto-electronics, 4, 87-99, doi:10.1007/BF01421174, 1972.

Cruz, C. N., , and Pandis, S. N.: Deliquescence and Hygroscopic Growth of Mixed Inorganic-Organic Atmospheric Aerosol, Environmental Science \& Technology, 34, 4313-4319, doi:10.1021/es9907109, 2000.

Diskin, G. S., Podolske, J. R., Sachse, G. W., and Slate, T. A.: Open-path airborne tunable diode laser hygrometer, doi:10.1117/12.453736, 2002.

20 Fernald, F. G.: Analysis of atmospheric lidar observations: some comments, Appl. Opt., 23, 652-653, doi:10.1364/AO.23.000652, 1984.

Gibson, E. R., Hudson, P. K., and Grassian, V. H.: Physicochemical Properties of Nitrate Aerosols: Implications for the Atmosphere, The Journal of Physical Chemistry A, 110, 11 785-11 799, doi:10.1021/jp063821k, 2006.

Gysel, M., Weingartner, E., and Baltensperger, U.: Hygroscopicity of aerosol particles at low temperatures. 2. Theoretical and experimental hygroscopic properties of laboratory generated aerosols, Environmental Science \& Technology, 36, 63-68, doi:10.1021/es010055g, 2002.

Hair, J. W., Hostetler, C. A., Cook, A. L., Harper, D. B., Ferrare, R. A., Mack, T. L., Welch, W., Izquierdo, L. R., and Hovis, F. E.: Airborne High Spectral Resolution Lidar for profiling aerosol optical properties, Appl. Opt., 47, 6734-6752, doi:10.1029/2001GL013691, 2008.

Hale, G. M. and Querry, M. R.: Optical Constants of Water in the 200-nm to 200- $\mu$ m Wavelength Region, Appl. Opt., 12, 555-563, doi:10.1364/AO.12.000555, 1973.

Holben, B. N., Eck, T. F., Slutsker, I., Tanré, D., Buis, J. P., Setzer, A., Vermote, E., Reagan, J. A., Kaufman, Y. J., Nakajima, T., Lavenu, F., Jankowiak, I., and Smirnov, A.: AERONET - A federated instrument network and data archive for aerosol characterization, Remote Sens. Environ., 66, 1-16, doi:10.1016/S0034-4257(98)00031-5, 1998.

Hu, D., Qiao, L., Chen, J., Ye, X., Cheng, T., and Fang, W.: Hygroscopicity of inorganic aerosols: size and relative humidity effects on the growth factor, Aerosol and Air Quality Research, 10, 255-264, doi:10.4209/aaqr.2009.12.0076, 2010.

Hu, D., Chen, J., Ye, X., Li, L., and Yang, X.: Hygroscopicity and evaporation of ammonium chloride and ammonium nitrate: Relative humidity and size effects on the growth factor, Atmospheric Environment, 45, 2349 - 2355, doi:http://dx.doi.org/10.1016/j.atmosenv.2011.02.024, 2011.

Kanakidou, M., Seinfeld, J. H., Pandis, S. N., Barnes, I., Dentener, F. J., Facchini, M. C., Van Dingenen, R., Ervens, B., Nenes, A., Nielsen, C. J., Swietlicki, E., Putaud, J. P., Balkanski, Y., Fuzzi, S., Horth, J., Moortgat, G. K., Winterhalter, R., Myhre, C. E. L., Tsigaridis, 
Atmos. Chem. Phys. Discuss., doi:10.5194/acp-2016-380, 2016

Atmospheric

Chemistry

Published: 17 May 2016

(c) Author(s) 2016. CC-BY 3.0 License.

and Physics

Discussions

(c) (i)

K., Vignati, E., Stephanou, E. G., and Wilson, J.: Organic aerosol and global climate modelling: a review, Atmospheric Chemistry and Physics, 5, 1053-1123, doi:10.5194/acp-5-1053-2005, 2005.

Kassianov, E., Pekour, M., and Barnard, J.: Aerosols in central California: Unexpectedly large contribution of coarse mode to aerosol radiative forcing, Geophysical Research Letters, 39, doi:10.1029/2012GL053469, 2012.

5 Kassianov, E., Berg, L. K., Pekour, M., Barnard, J., Chand, D., Flynn, C., Ovchinnikov, M., Sedlacek, A., Schmid, B., Shilling, J., Tomlinson, J., and Fast, J.: Airborne Aerosol in Situ Measurements during TCAP: A Closure Study of Total Scattering, Atmosphere, 6, 1069, doi:10.3390/atmos6081069, 2015.

Kasten, F.: Visibility forecast in the phase of pre-condensation, Tellus, 21, 631-635, doi:10.1111/j.2153-3490.1969.tb00469.x, 1969.

Kotchenruther, R. A. and Hobbs, P. V.: Humidification factors of aerosols from biomass burning in Brazil, Journal of Geophysical Research: Atmospheres, 103, 32 081-32 089, doi:10.1029/98JD00340, 1998.

Kotchenruther, R. A., Hobbs, P. V., and Hegg, D. A.: Humidification factors for atmospheric aerosols off the mid-Atlantic coast of the United States, Journal of Geophysical Research: Atmospheres, 104, 2239-2251, doi:10.1029/98JD01751, 1999.

Kovalev, V. A. and Eichinger, W. E.: Elastic lidar: theory, practice, and analysis methods, John Wiley \& Sons, 2004.

Liu, Y. and Daum, P. H.: The effect of refractive index on size distributions and light scattering coefficients derived from optical particle counters, J. Atmos. Sci., 31, 945 - 957, doi:10.1016/S0021-8502(99)00573-X, 2000.

Liu, Z., Hunt, W., Vaughan, M., Hostetler, C., McGill, M., Powell, K., Winker, D., and Hu, Y.: Estimating random errors due to shot noise in backscatter lidar observations, Appl. Opt., 45, 4437-4447, doi:10.1364/AO.45.004437, 2006.

Lurmann, F. W., Brown, S. G., McCarthy, M. C., and Roberts, P. T.: Processes Influencing Secondary Aerosol Formation in the San Joaquin Valley during Winter, Journal of the Air \& Waste Management Association, 56, 1679-1693, doi:10.1080/10473289.2006.10464573, 2006.

Mamouri, R. E. and Ansmann, A.: Fine and coarse dust separation with polarization lidar, Atmospheric Measurement Techniques, 7, 37173735, doi:10.5194/amt-7-3717-2014, 2014.

Martin, S. T.: Phase Transitions of Aqueous Atmospheric Particles, Chemical Reviews, 100, 3403-3454, doi:10.1021/cr990034t, 2000.

McFarquhar, G., Schmid, B., Korolev, A., Ogren, J. A., Russell, P. B., Tomlinson, J., Turner, D. D., and Wiscombe, W.: Airborne Instrumentation Needs for Climate and Atmospheric Research, Bull. Amer. Meteor. Soc., 92, 1193-1196, 2011.

McNaughton, C. S., Clarke, A. D., Howell, S. G., Pinkerton, M., Anderson, B., Thornhill, L., Hudgins, C., Winstead, E., Dibb, J. E., Scheuer, E., and Maring, H.: Results from the DC-8 Inlet Characterization Experiment (DICE): Airborne Versus Surface Sampling of Mineral Dust and Sea Salt Aerosols, Aerosol Science and Technology, 41, 136-159, doi:10.1080/02786820601118406, 2007.

Mie, G.: Beiträge zur Optik trüber Medien, speziell kolloidaler Metallösungen, Annalen der Physik, 25, 377-445, doi:10.1002/andp.19083300302, 1908.

Müller, D., Tesche, M., Eichler, H., Engelmann, R., Althausen, D., Ansmann, A., Cheng, Y. F., Zhang, Y. H., and Hu, M.: Strong particle light absorption over the Pearl River Delta (south China) and Beijing (north China) determined from combined Raman lidar and Sun photometer observations, Geophys. Res. Lett., 33, doi:10.1029/2006GL027196, 2006.

Müller, D., Wandinger, U., Althausen, D., Mattis, I., and Ansmann, A.: Retrieval of physical particle properties from lidar observations of extinction and backscatter at multiple wavelengths, Applied Optics, 37, 2260-2263, doi:10.1364/AO.37.002260, 1998.

Müller, D., Wandinger, U., and Ansmann, A.: Microphysical particle parameters from extinction and backscatter lidar data by inversion with regularization: Theory, Appl. Opt., 38, 2346-2357, doi:10.1364/AO.38.002346, 1999a.

Müller, D., Wandinger, U., and Ansmann, A.: Microphysical particle parameters from extinction and backscatter lidar data by inversion with regularization: simulation, Appl. Opt., 38, 2358-2368, doi:10.1364/AO.38.002358, 1999b. 
Atmos. Chem. Phys. Discuss., doi:10.5194/acp-2016-380, 2016

Atmospheric

Chemistry

Published: 17 May 2016

(c) Author(s) 2016. CC-BY 3.0 License.

and Physics

Discussions

(c) (i)

Müller, D., Wandinger, U., Althausen, D., and Fiebig, M.: Comprehensive particle characterization from three-wavelength Raman-lidar observations: Case study, Appl. Opt., 40, 4863-4869, doi:10.1364/AO.40.004863, 2001.

Müller, D., Franke, K., Ansmann, A., Althausen, D., and Wagner, F.: Indo-Asian pollution during INDOEX: Microphysical particle properties and single-scattering albedo inferred from multiwavelength lidar observations, J. Geophys. Res, 108, doi:10.1029/2003JD003538, 2003.

5 Müller, D., Hostetler, C. A., Ferrare, R. A., Burton, S. P., Chemyakin, E., Kolgotin, A., Hair, J. W., Cook, A. L., Harper, D. B., Rogers, R. R., Hare, R. W., Cleckner, C. S., Obland, M. D., Tomlinson, J., Berg, L. K., and Schmid, B.: Airborne Multiwavelength High Spectral Resolution Lidar (HSRL-2) observations during TCAP 2012: vertical profiles of optical and microphysical properties of a smoke/urban haze plume over the northeastern coast of the US, Atmos. Meas. Tech., 7, 3487-3496, doi:10.5194/amt-7-3487-2014, 2014.

Murayama, T., Müller, D., Wada, K., Shimizu, A., Sekiguchi, M., and Tsukamoto, T.: Characterization of Asian dust and Siberian smoke with multi-wavelength Raman lidar over Tokyo, Japan in spring 2003, Geophys. Res. Lett., 31, doi:10.1029/2004GL021105, 2004.

Navas-Guzmán, F., Müller, D., Bravo-Aranda, J. A., Guerrero-Rascado, J. L., Granados-Muñoz, M. J., Pérez-Ramírez, D., Olmo, F. J., and Alados-Arboledas, L.: Eruption of the Eyjafjallajökull Volcano in spring 2010: Multiwavelength Raman lidar measurements of sulphate particles in the lower troposphere, J. Geophys. Res., 118, 1804-1813, doi:10.1002/jgrd.50116, 2013.

Nicolae, D., Nemuc, A., Müller, D., Talianu, C., Vasilescu, J., Belegante, L., and Kolgotin, A.: Characterization of fresh and aged biomass burning events using multiwavelength Raman lidar and mass spectrometry, J. Geophys. Res., 118, 2956-2965, doi:10.1002/jgrd.50324, 2013.

Noh, Y. M., Müller, D., Shin, D. H., Lee, H., Jung, J., Lee, K. H., Cribb, M., Li, Z., and Kim, Y. J.: Optical and microphysical properties of severe haze and smoke aerosol measured by integrated remote sensing techniques in Gwangju, Korea, Atmos. Environ., 43, 879-888, doi:10.1016/j.atmosenv.2008.10.058, 2009.

O’Neill, N. T., Eck, T. F., Holben, B. N., Smirnov, A., Dubovik, O., and Royer, A.: Bimodal size distribution influences on the variation of Angstrom derivatives in spectral and optical depth space, Journal of Geophysical Research: Atmospheres, 106, 9787-9806, doi:10.1029/2000JD900245, 2001.

Petters, M. D. and Kreidenweis, S. M.: A single parameter representation of hygroscopic growth and cloud condensation nucleus activity, Atmos. Chem. Phys., 7, 1961-1971, doi:10.5194/acp-7-1961-2007, 2007.

Pilat, M. J. and Charlson, R. J.: Theoretical and optical studies of humidty effects on the size distribution of a hygroscopic aerosol, J. Rech. Atmos., pp. 165-170, 1966.

Pinnick, R. G., Pendleton, J. D., and Videen, G.: Response Characteristics of the Particle Measuring Systems Active Scattering Aerosol Spectrometer Probes, Aerosol Science and Technology, 33, 334-352, doi:10.1080/02786820050121530, 2000.

Pringle, K. J., Tost, H., Pozzer, A., Pöschl, U., and Lelieveld, J.: Global distribution of the effective aerosol hygroscopicity parameter for CCN activation, Atmospheric Chemistry and Physics, 10, 5241-5255, doi:10.5194/acp-10-5241-2010, 2010.

Pusede, S. E., Duffey, K. C., Shusterman, A. A., Saleh, A., Laughner, J. L., Wooldridge, P. J., Zhang, Q., Parworth, C. L., Kim, H., Capps, S. L., Valin, L. C., Cappa, C. D., Fried, A., Walega, J., Nowak, J. B., Weinheimer, A. J., Hoff, R. M., Berkoff, T. A., Beyersdorf, A. J., Olson, J., Crawford, J. H., and Cohen, R. C.: On the effectiveness of nitrogen oxide reductions as a control over ammonium nitrate aerosol, Atmospheric Chemistry and Physics, 16, 2575-2596, doi:10.5194/acp-16-2575-2016, 2016.

Qing, P., Nakane, H., Sasano, Y., and Kitamura, S.: Numerical simulation of the retrieval of aerosol size distribution from multiwavelength laser radar measurements, Appl. Opt., 28, 5259-5265, doi:10.1364/AO.28.005259, 1989.

Rader, D. and McMurry, P.: Application of the tandem differential mobility analyzer to studies of droplet growth or evaporation, Journal of Aerosol Science, 17, 771 - 787, doi:10.1016/0021-8502(86)90031-5, 1986. 
Atmos. Chem. Phys. Discuss., doi:10.5194/acp-2016-380, 2016

Atmospheric

Chemistry

Published: 17 May 2016

(c) Author(s) 2016. CC-BY 3.0 License.

and Physics

Discussions

(c) $\underset{\mathrm{By}}{\mathrm{i}}$

Sawamura, P., Müller, D., Hoff, R. M., Hostetler, C. A., Ferrare, R. A., Hair, J. W., Rogers, R. R., Anderson, B. E., Ziemba, L. D., Beyersdorf, A. J., Thornhill, K. L., Winstead, E. L., and Holben, B. N.: Aerosol optical and microphysical retrievals from a hybrid multiwavelength lidar data set - DISCOVER-AQ 2011, Atmos. Meas. Tech., 7, 3095-3112, doi:10.5194/amt-7-3095-2014, 2014.

Saxena, P., Hildemann, L. M., McMurry, P. H., and Seinfeld, J. H.: Organics alter hygroscopic behavior of atmospheric particles, Journal of

Geophysical Research: Atmospheres, 100, 18 755-18770, doi:10.1029/95JD01835, 1995.

Shipley, S. T., Tracy, D. H., Eloranta, E. W., Trauger, J. T., Sroga, J. T., Roesler, F. L., and Weinman, J. A.: High spectral resolution lidar to measure optical scattering properties of atmospheric aerosols. 1: Theory and instrumentation, Appl. Opt., 22, 3716-3724, doi:10.1364/AO.22.003716, 1983 .

Smith, M. L., Bertram, A. K., and Martin, S. T.: Deliquescence, efflorescence, and phase miscibility of mixed particles of ammonium sulfate and isoprene-derived secondary organic material, Atmospheric Chemistry and Physics, 12, 9613-9628, doi:10.5194/acp-12-9613-2012, 2012.

Solarz, R. and Paisner, J.: Laser Spectroscopy and its Applications, Optical Science and Engineering, Taylor \& Francis, 1986.

Sullivan, A. P. and Weber, R. J.: Chemical characterization of the ambient organic aerosol soluble in water: 1. Isolation of hydrophobic and hydrophilic fractions with a XAD-8 resin, Journal of Geophysical Research: Atmospheres, 111, doi:10.1029/2005JD006485, 2006.

Tang, I., Munkelwitz, H., and Davis, J.: Aerosol growth studies - IV. Phase transformation of mixed salt aerosols in a moist atmosphere, Journal of Aerosol Science, 9, 505 - 511, doi:http://dx.doi.org/10.1016/0021-8502(78)90015-0, 1978.

Tesche, M., Müller, D., Ansmann, A., Hu, M., and Zhang, Y.: Retrieval of microphysical properties of aerosol particles from one-wavelength Raman lidar and multiwavelength Sun photometer observations, Atmos. Environ., 42, 6398-6404, doi:10.1016/j.atmosenv.2008.02.014, 2008.

Veselovskii, I., Kolgotin, A., Griaznov, V., Müller, D., Wandinger, U., and Whiteman, D. N.: Inversion with regularization for the retrieval of tropospheric aerosol parameters from multiwavelength lidar sounding, Appl. Opt., 41, 3685-3699, doi:10.1364/AO.41.003685, 2002.

Veselovskii, I., Whiteman, D. N., Kolgotin, A., Andrews, E., and Korenskii, M.: Demonstration of aerosol property profiling by multiwavelength lidar under varying relative humidity conditions, J. Atmos. Oceanic Technol., 26, 1543-1557, doi:10.1175/2009JTECHA1254.1, 2009.

Virkkula, A.: Correction of the Calibration of the 3-wavelength Particle Soot Absorption Photometer (3 $\lambda$ PSAP), Aerosol Science and Technology, 44, 706-712, doi:10.1080/02786826.2010.482110, 2010.

Wandinger, U., Müller, D., Böckmann, C., Althausen, D., Matthias, V., Bösenberg, J., Weiß, Fiebig, M., Wendisch, M., Stohl, A., and Ansmann, A.: Optical and microphysical characterization of biomass-burning and industrial-pollution aerosols from multiwavelength lidar and aircraft measurements, J. Geophys. Res, 107, doi:10.1029/2000JD000202, 2002.

Watson, J. G. and Chow, J. C.: A wintertime PM2.5 episode at the Fresno, CA, supersite, Atmospheric Environment, 36,465 - 475 , doi:http://dx.doi.org/10.1016/S1352-2310(01)00309-0, 2002.

Weitkamp, C.: Lidar: Range-resolved optical remote sensing of the atmosphere, Springer Series in Optical Sciences, Springer, doi:10.1007/b106786, 2005.

Zhang, K. M. and Wexler, A. S.: Modeling the number distributions of urban and regional aerosols: theoretical foundations, Atmospheric Environment, 36, 1863 - 1874, doi:10.1016/S1352-2310(02)00095-X, 2002.

Zieger, P., Fierz-Schmidhauser, R., Gysel, M., Ström, J., Henne, S., Yttri, K. E., Baltensperger, U., and Weingartner, E.: Effects of relative humidity on aerosol light scattering in the Arctic, Atmos. Chem. Phys., 10, 3875-3890, doi:10.5194/acp-10-3875-2010, http://www. atmos-chem-phys.net/10/3875/2010/, 2010. 
Atmos. Chem. Phys. Discuss., doi:10.5194/acp-2016-380, 2016

Manuscript under review for journal Atmos. Chem. Phys.

Published: 17 May 2016

(c) Author(s) 2016. CC-BY 3.0 License.

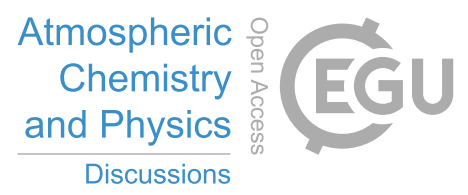

(c) (1)

Zieger, P., Weingartner, E., Henzing, J., Moerman, M., de Leeuw, G., Mikkilä, J., Ehn, M., Petäjä, T., Clémer, K., van Roozendael, M., Yilmaz, S., Frieß, U., Irie, H., Wagner, T., Shaiganfar, R., Beirle, S., Apituley, A., Wilson, K., and Baltensperger, U.: Comparison of ambient aerosol extinction coefficients obtained from in-situ, MAX-DOAS and LIDAR measurements at Cabauw, Atmospheric Chemistry and Physics, 11, 2603-2624, doi:10.5194/acp-11-2603-2011, 2011.

5 Ziemba, L. D., Lee Thornhill, K., Ferrare, R., Barrick, J., Beyersdorf, A. J., Chen, G., Crumeyrolle, S. N., Hair, J., Hostetler, C., Hudgins, C., Obland, M., Rogers, R., Scarino, A. J., Winstead, E. L., and Anderson, B. E.: Airborne observations of aerosol extinction by in situ and remote-sensing techniques: Evaluation of particle hygroscopicity, Geophys. Res. Lett., 40, 417-422, doi:10.1029/2012GL054428, 2013. 
Atmos. Chem. Phys. Discuss., doi:10.5194/acp-2016-380, 2016

Manuscript under review for journal Atmos. Chem. Phys.

Published: 17 May 2016

(c) Author(s) 2016. CC-BY 3.0 License.

(c) (i)

Table 1. Sign table used in the HSRl-2 retrieval algorithm to disturb the input data (i.e. $3 \beta+2 \alpha$ ) with their respective uncertainties. For instance, the first run of the inversion algorithm starts with an input set comprised of $\alpha_{355}+\Delta \alpha_{355}, \alpha_{532}+\Delta \alpha_{532}, \beta_{355}+\Delta \beta_{355}, \beta_{532}+$ $\Delta \beta_{532}, \beta_{1064}-\Delta \beta_{1064}$, where $\Delta$ s refer to uncertainties.

\begin{tabular}{c|ccccc}
\hline Run number & $\alpha_{355}$ & $\alpha_{532}$ & $\beta_{355}$ & $\beta_{532}$ & $\beta_{1064}$ \\
\hline 1 & + & + & + & + & - \\
2 & - & - & + & + & - \\
3 & + & - & + & + & - \\
4 & - & + & + & + & - \\
5 & + & + & - & - & + \\
6 & - & - & - & - & + \\
7 & + & - & - & - & + \\
8 & - & + & - & - & + \\
\hline
\end{tabular}

Table 2. Percent number of $3 \beta+2 \alpha$ retrievals with biases smaller than $50 \%$ as obtained from preliminary results of a sensitve study with simulated data, and from this study.

\begin{tabular}{ccccc}
\hline & N & S-A & V & $\mathbf{R}_{\text {eff }}$ \\
\hline Simulations & $40-60 \%$ & $90-100 \%$ & $60-80 \%$ & $80 \%$ \\
This study & $56 \%$ & $81 \%$ & $86 \%$ & $96 \%$ \\
\hline
\end{tabular}

Table 3. Parameters of bisector linear regression fit between the HSRL- 2 measurements $(\mathrm{x})$ and the reconstructed version of $3 \beta+2 \alpha$ (y: from in-situ measurements). The columns under UHSAS contain the parameters from the linear regressions depicted as red dashed lines in Figure 7. The column under LAS contains the parameters from the linear regressions obtained when the reconstructed version (y) is calculated using LAS measurements instead of UHSAS measurements (not shown, see text). R refers to the Pearson's correlation coefficient.

\begin{tabular}{|c|c|c|c|}
\hline & \multicolumn{2}{|c|}{ UHSAS } & LAS \\
\hline & DAQ CA & DAQ TX & DAQ CA \\
\hline$\alpha_{355}$ & $y=0.77 x-23.2, R=0.89$ & $y=0.66 x+7.6, R=0.88$ & $y=0.84 x-26.5, R=0.90$ \\
$\alpha_{532}$ & $y=0.94 x-20.4, R=0.88$ & $y=0.67 x+4.1, R=0.86$ & $y=0.98 x-19.4, R=0.91$ \\
$\beta_{355}$ & $y=1.13 x-1.7, R=0.88$ & $y=0.57 x-0.1, R=0.72$ & $y=0.98 x-1.1, R=0.89$ \\
$\beta_{532}$ & $y=1.26 x-1.4, R=0.86$ & $y=0.55 x-0.01, R=0.79$ & $y=1.08 x-0.96, R=0.88$ \\
$\beta_{1064}$ & $y=0.81 x-0.34, R=0.83$ & $y=0.51 x+0.03, R=0.46$ & $y=1.02 x-0.40, R=0.80$ \\
\hline
\end{tabular}


Atmos. Chem. Phys. Discuss., doi:10.5194/acp-2016-380, 2016

Manuscript under review for journal Atmos. Chem. Phys.

Published: 17 May 2016

(c) Author(s) 2016. CC-BY 3.0 License.

(c) (i)
Atmospheric

Chemistry

and Physics

Discussions

Table 4. Mean reproduced fraction of extinction $(\alpha)$ and backscatter $(\beta)$ coefficients at cut-off diameters $\mathrm{D}_{\text {cut }}=1.2,0.7$, and $0.4 \mu m$ for size distributions (SZD) 1-4 (Figure 11).

\begin{tabular}{cccc}
\hline & $1.2 \mu m$ & $0.7 \mu m$ & $0.4 \mu m$ \\
\hline$\alpha_{355}$ & $0.91 \pm 0.02$ & $0.83 \pm 0.08$ & $0.65 \pm 0.12$ \\
$\alpha_{532}$ & $0.85 \pm 0.05$ & $0.66 \pm 0.13$ & $0.41 \pm 0.11$ \\
$\beta_{355}$ & $0.85 \pm 0.05$ & $0.63 \pm 0.15$ & $0.45 \pm 0.13$ \\
$\beta_{532}$ & $0.72 \pm 0.07$ & $0.52 \pm 0.14$ & $0.38 \pm 0.08$ \\
$\beta_{1064}$ & $0.53 \pm 0.07$ & $0.32 \pm 0.13$ & $0.23 \pm 0.10$ \\
\hline
\end{tabular}

Table A1. Range of parameters of the bimodal size distributions used in the simulations to assess the effect of the diameter-independence assumption in the retrieval of effective growth factors from the in situ measurements.

\begin{tabular}{ccccc}
\hline & \multicolumn{2}{c}{ California } & \multicolumn{2}{c}{ Texas } \\
& $1^{s t}$ mode & $2^{n d}$ mode & $1^{s t}$ mode & $2^{n d}$ mode \\
\hline$N\left(\mathrm{~cm}^{-3}\right)$ & $0.94-0.97$ & $1-\mathrm{N}_{1}$ & $0.94-0.97$ & $1-\mathrm{N}_{1}$ \\
$\sigma$ & $1.50-1.65$ & $1.50-2.20$ & $1.20-1.70$ & $1.20-1.90$ \\
$\mathrm{D}_{m}(\mathrm{~nm})$ & $20-100$ & $80-170$ & $10-280$ & $100-280$ \\
$m_{R}$ & $1.50-1.65$ & $1.55-1.70$ & $1.55-1.64$ & $1.50-1.55$ \\
$m_{I}$ & $0.001-0.01$ & $0.001-0.01$ & $0.003-0.02$ & $0.003-0.01$ \\
$g$ & $1-1.25$ & $1-1.30$ & $1-1.4$ & $1.1-1.4$ \\
\hline
\end{tabular}


Atmos. Chem. Phys. Discuss., doi:10.5194/acp-2016-380, 2016

Manuscript under review for journal Atmos. Chem. Phys.

Published: 17 May 2016

(C) Author(s) 2016. CC-BY 3.0 License.
Atmospheric

Chemistry

and Physics

Discussions

(c) (1)

Table A2. Correlation coefficient, RMSE and bias from simulations to evaluate the retrieval algorithm used with the in situ data. " $20 \%$, $10 \%$, $20 \%$ errors" refers to the scenario that considers up to $20 \%$ error for the dry size distribution, up to $10 \%$ for the dry optical data, and up to $20 \%$ for the ambient scattering coefficient at $550 \mathrm{~nm}$.

\begin{tabular}{|c|c|c|c|c|c|c|}
\hline \multirow[b]{2}{*}{ DAQ CA } & \multicolumn{3}{|c|}{ Noise-free scenario } & \multicolumn{3}{|c|}{$20 \%, 10 \%, 20 \%$ errors } \\
\hline & $\mathrm{R}$ & $\operatorname{RMSE}(\%)$ & Bias $(\%)$ & $\mathrm{R}$ & RMSE (\%) & Bias $(\%)$ \\
\hline$m R_{d r y}$ & 1.00 & 0.23 & 0.00 & $0.91 \pm 0.01$ & $1.16 \pm 0.05$ & $-0.08 \pm 0.08$ \\
\hline$m I_{d r y}$ & 0.97 & 11.8 & 1.88 & $0.81 \pm 0.02$ & $31.2 \pm 2.2$ & $9.12 \pm 0.67$ \\
\hline$m R_{a m b}$ & 0.50 & 3.93 & -2.58 & $0.46 \pm 0.03$ & $4.15 \pm 0.08$ & $-2.62 \pm 0.07$ \\
\hline$m I_{a m b}$ & 0.79 & 41.2 & -19.9 & $0.66 \pm 0.02$ & $49.2 \pm 2.3$ & $-14.6 \pm 1.1$ \\
\hline$S_{a m b}$ & 0.98 & 33.4 & 27.8 & $0.96 \pm 0.00$ & $38.6 \pm 1.8$ & $28.4 \pm 1.1$ \\
\hline$V_{a m b}$ & 0.99 & 23.7 & 19.7 & $0.97 \pm 0.00$ & $25.9 \pm 0.8$ & $19.7 \pm 0.6$ \\
\hline$R_{e f f_{a m b}}$ & 0.99 & 8.36 & 6.49 & $0.98 \pm 0.00$ & $9.9 \pm 0.3$ & $6.5 \pm 0.2$ \\
\hline
\end{tabular}

\begin{tabular}{|c|c|c|c|c|c|c|}
\hline & \multicolumn{3}{|c|}{ Noise-free scenario } & \multicolumn{3}{c|}{ 20\%, 10\%, 20\% errors } \\
\hline DAQ TX & $\mathrm{R}$ & RMSE (\%) & Bias (\%) & $\mathrm{R}$ & RMSE $(\%)$ & Bias (\%) \\
\hline$m R_{d r y}$ & 0.99 & 0.21 & 0.01 & $0.87 \pm 0.02$ & $1.07 \pm 0.06$ & $0.04 \pm 0.07$ \\
$m I_{d r y}$ & 0.88 & 21.4 & 2.99 & $0.64 \pm 0.05$ & $36.6 \pm 2.9$ & $13.5 \pm 2.3$ \\
$m R_{a m b}$ & 0.81 & 3.75 & -3.12 & $0.73 \pm 0.02$ & $3.91 \pm 0.06$ & $-3.03 \pm 0.08$ \\
$m I_{a m b}$ & 0.86 & 43.9 & -27.2 & $0.70 \pm 0.04$ & $47.5 \pm 2.0$ & $-20.0 \pm 1.6$ \\
$S_{a m b}$ & 0.98 & 47.9 & 38.3 & $0.97 \pm 0.01$ & $53.7 \pm 1.2$ & $39.3 \pm 1.1$ \\
$V_{a m b}$ & 0.99 & 30.1 & 25.0 & $0.98 \pm 0.00$ & $32.9 \pm 0.6$ & $25.4 \pm 0.6$ \\
$R_{e f f_{a m b}}$ & 0.98 & 12.1 & 10.3 & $0.97 \pm 0.00$ & $12.9 \pm 0.2$ & $10.4 \pm 0.2$ \\
\hline
\end{tabular}


Atmos. Chem. Phys. Discuss., doi:10.5194/acp-2016-380, 2016

Manuscript under review for journal Atmos. Chem. Phys.

Published: 17 May 2016

(c) Author(s) 2016. CC-BY 3.0 License.

(c) (i)
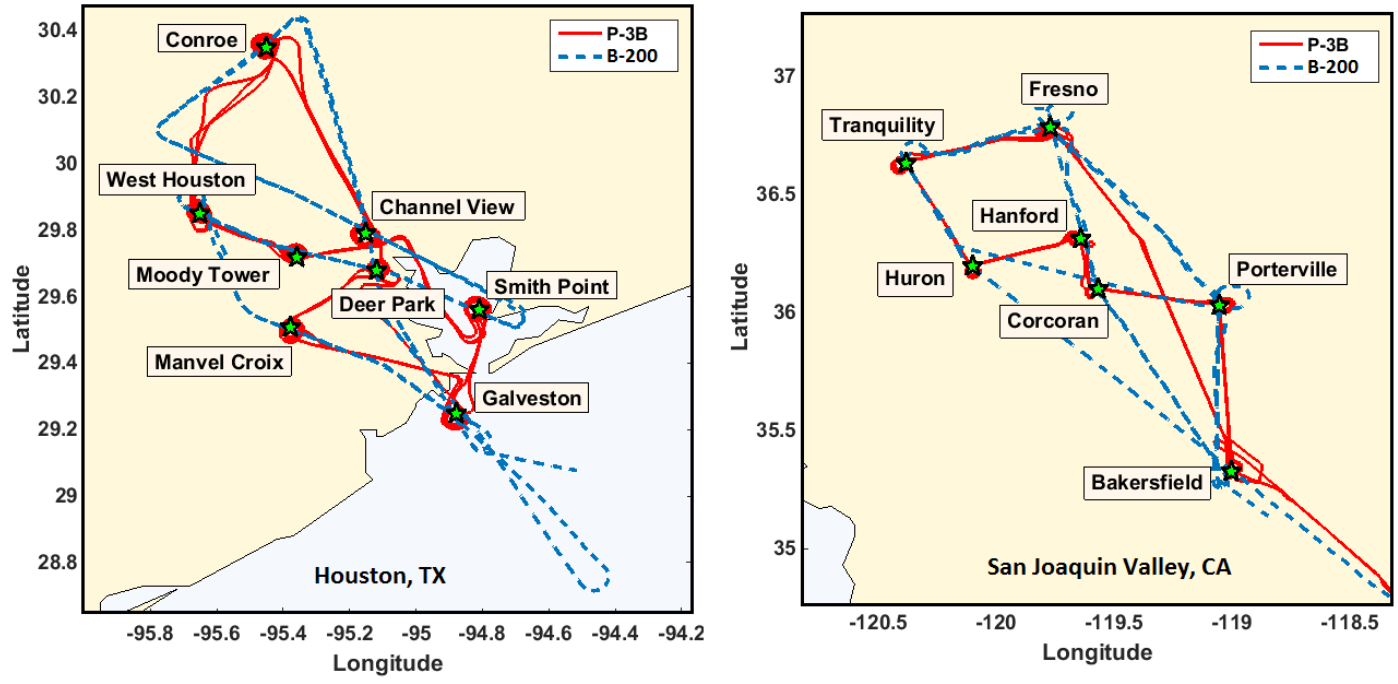

Figure 1. Map of the flight tracks for DAQ California (right) and DAQ Texas (left). The green stars mark the location of the ground stations over which the P3B (red solid line) spiraled. The HSRL-2 instrument onboard the King Air (blue dashed line) flew over the same ground stations. 
Atmos. Chem. Phys. Discuss., doi:10.5194/acp-2016-380, 2016

Manuscript under review for journal Atmos. Chem. Phys.

Published: 17 May 2016

(c) Author(s) 2016. CC-BY 3.0 License.

(c) (i)
Atmospheric

Chemistry

and Physics

Discussions

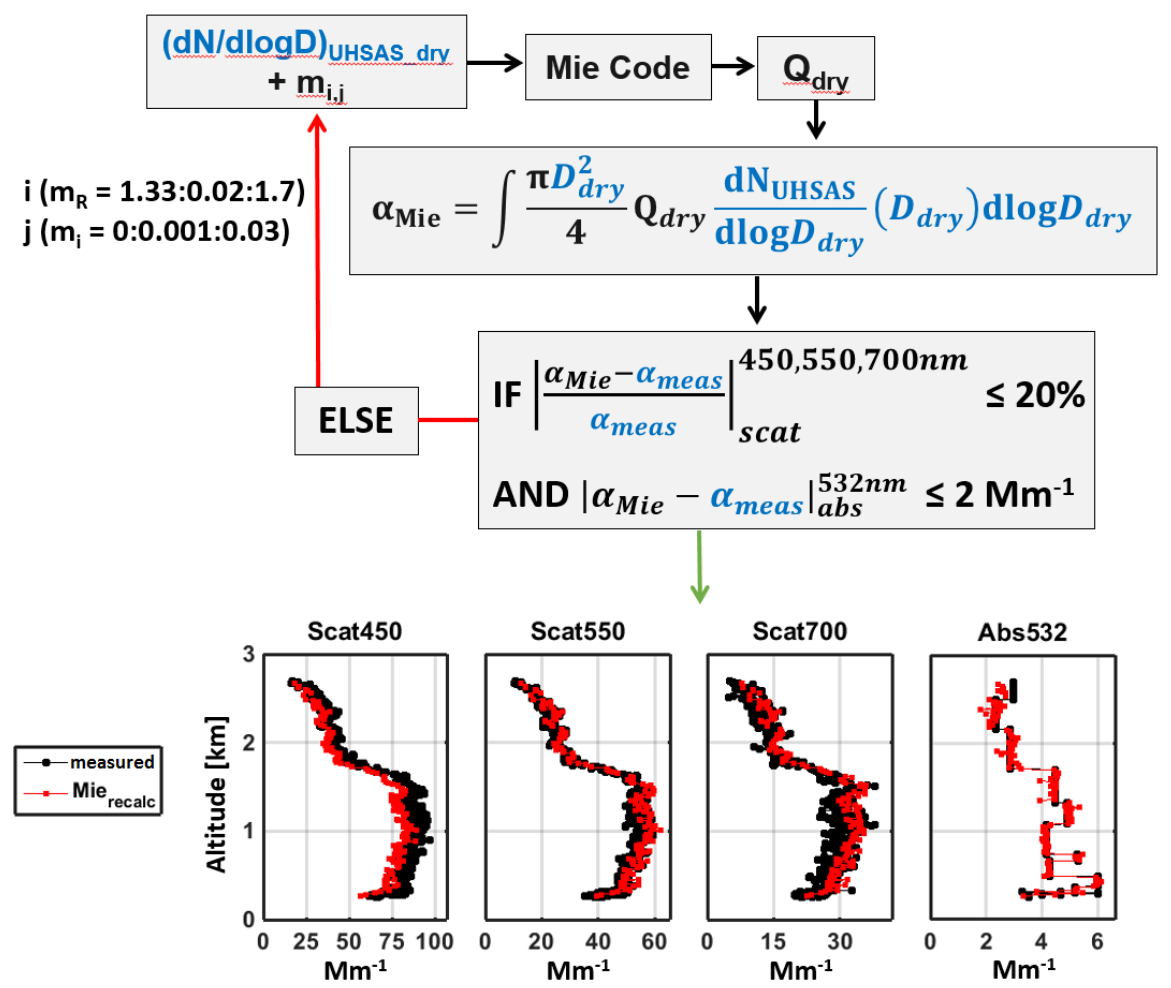

Figure 2. Diagram representation of Part $\mathrm{I}$ in which the dry complex refractive index $\mathrm{m}_{d r y}$ is retrieved from the in situ measurements. The blue terms in the block diagram refer to measured quantities. $\mathrm{Q}_{d r y}$ refers to the scattering or absorption efficiencies calculated with the Mie code. The profiles shown at the bottom of this figure were obtained over Channel View on September 11 ${ }^{\text {th }}$, 2013 between 21:06 - 21:15 UTC, during DAQ TX. The plots show the comparison between the in situ measurements ("P3B dry" in black) and the recalculated ("Mie ${ }_{\text {recalc" }}$ dry scattering at $450 \mathrm{~nm}$ (Scat450), $550 \mathrm{~nm}$ (Scat550), and $700 \mathrm{~nm}$ (Scat700), and absorption at $532 \mathrm{~nm}$ (Abs532) obtained with the complex refractive index retrieved in this step. 
Atmos. Chem. Phys. Discuss., doi:10.5194/acp-2016-380, 2016

Manuscript under review for journal Atmos. Chem. Phys.

Published: 17 May 2016

(c) Author(s) 2016. CC-BY 3.0 License.
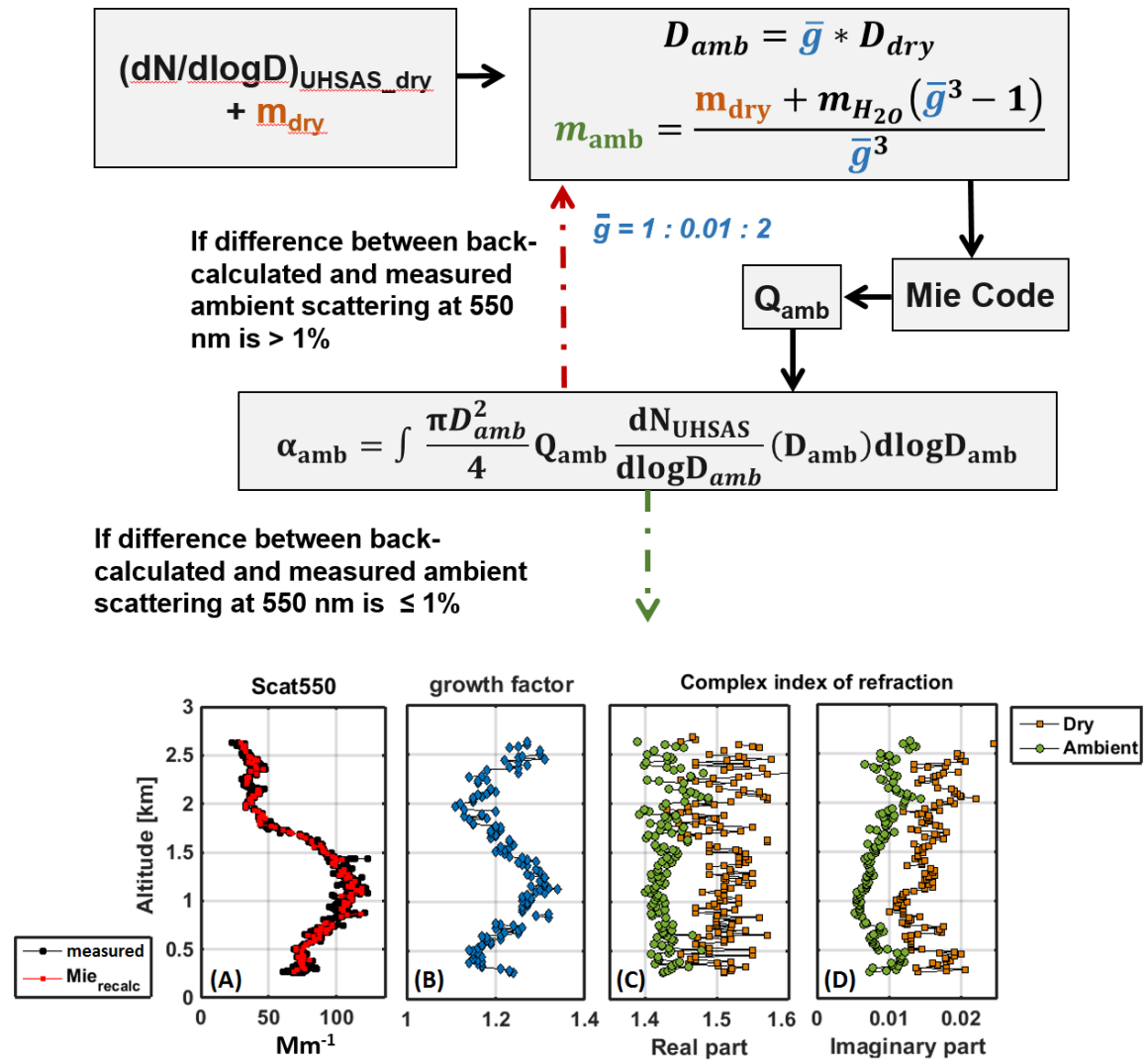

Figure 3. Diagram representation of Part II in which effective growth factor $\bar{g}$ and ambient complex refractive index $\mathrm{m}_{a m b}$ are retrieved using in situ data. The profiles shown at the bottom of this figure were obtained over the Houston area, on September $11^{\text {th }}$, 2013 between $21: 06$ - 21:15 UTC, during DAQ TX . (A) Comparison between the vertical profiles of measured ambient scattering at $550 \mathrm{~nm}$ and its calculated version. (B) Retrieved $\bar{g}$. Retrieved $m_{d r y}$ and $m_{a m b}$ : (C) real part, (D) imaginary part. 
Atmos. Chem. Phys. Discuss., doi:10.5194/acp-2016-380, 2016

Manuscript under review for journal Atmos. Chem. Phys.

Published: 17 May 2016

(c) Author(s) 2016. CC-BY 3.0 License.
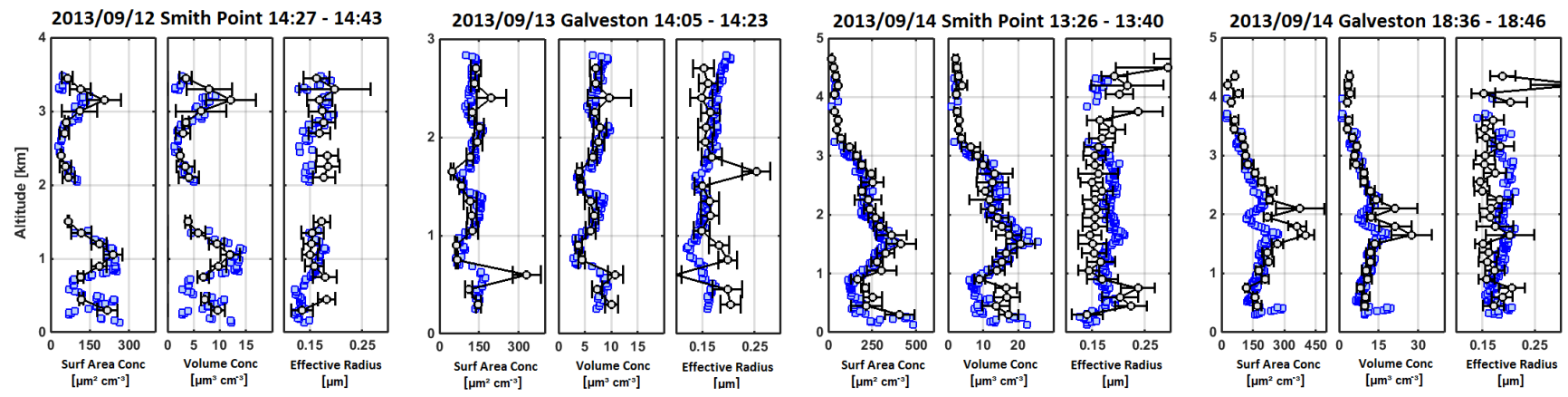

ㅁ In situ (amb) $\quad$ -

Figure 4. Examples of profile-to-profile comparisons between HSRL-2 retrievals and in situ measurements (corrected for ambient RH) of surface-area and volume concentrations, and effective radius obtained during DAQ TX. The error bars represent the uncertainties of the HSRL-2 retrieval.
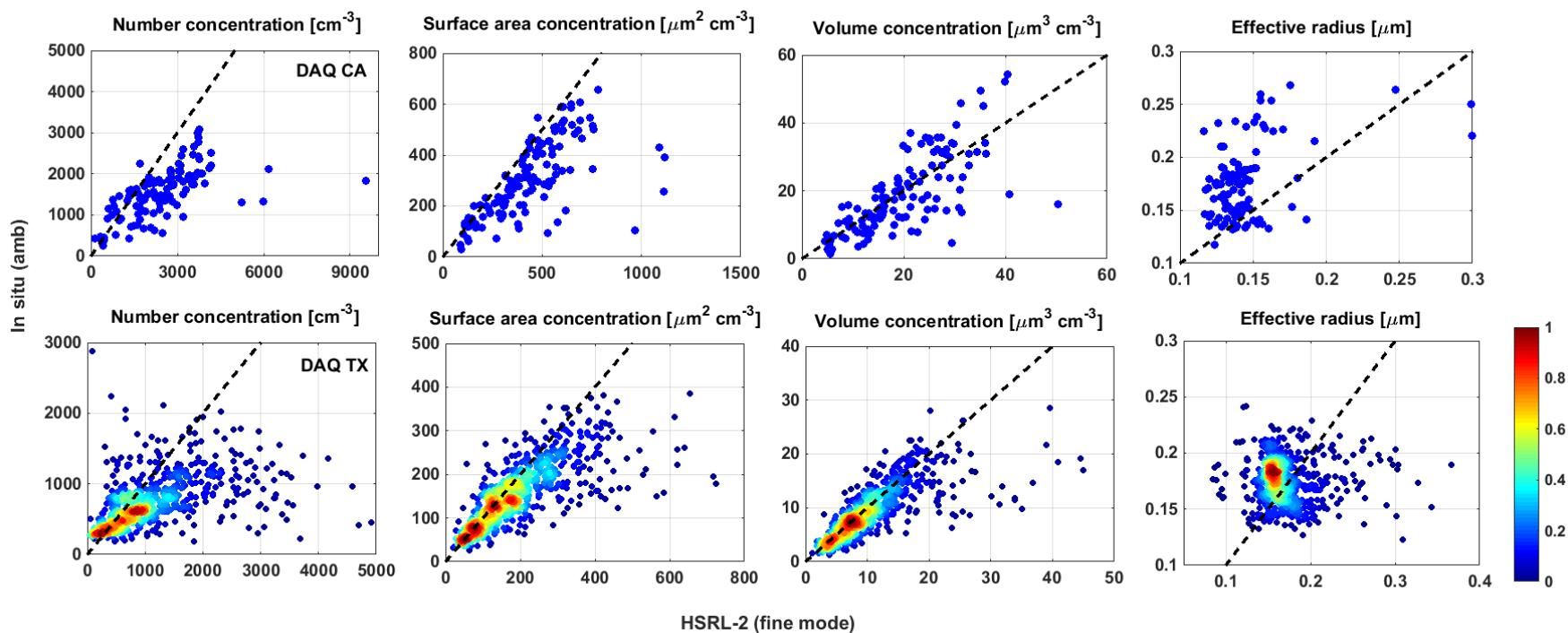

Figure 5. Comparison of number, surface-area and volume concentrations, and effective radius for all coincident points between HSRL-2 (x-axis) and in situ (corrected for ambient RH, y-axis) obtained during DAQ CA and TX. The black dashed lines represent 1:1. There are 126 points in the DAQ CA plots and 630 data points in the DAQ TX plots. For the latter, due to the large number of overlapping points, the scatter plot is color-coded by the density of points. The colorbar is normalized to 1 . 
Atmos. Chem. Phys. Discuss., doi:10.5194/acp-2016-380, 2016

Manuscript under review for journal Atmos. Chem. Phys.

Published: 17 May 2016

(c) Author(s) 2016. CC-BY 3.0 License.

(c) (i)
DAQ CA

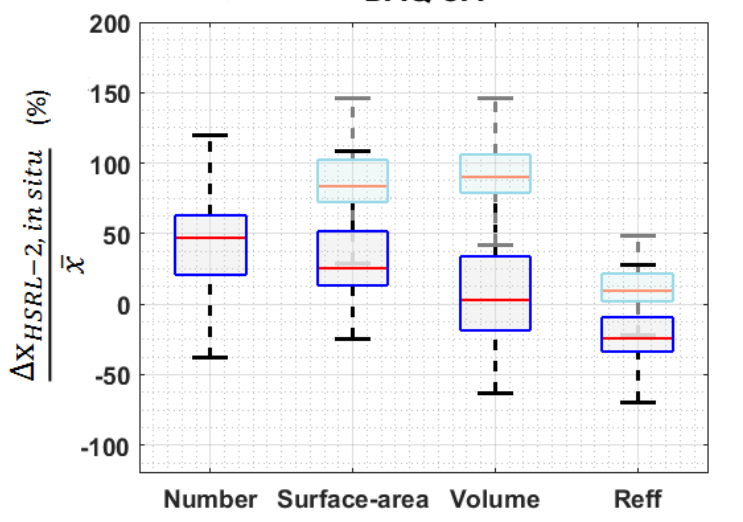

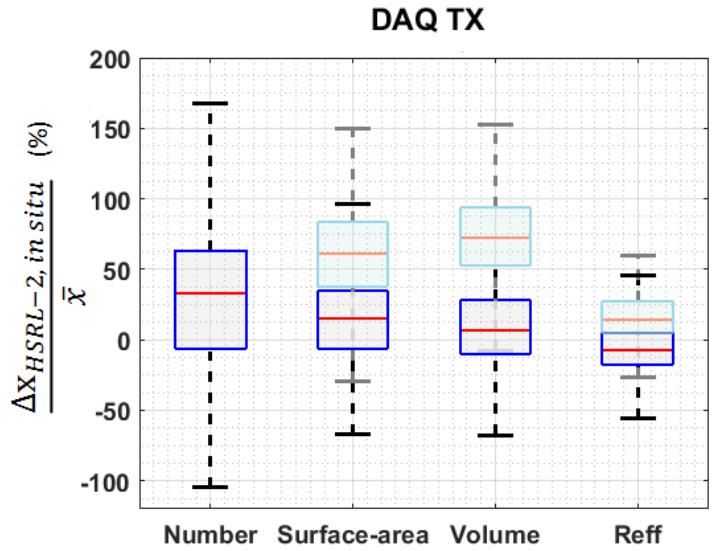

Without hygroscopic correction

Figure 6. Statistics of the comparison between the HSRL-2 retrievals and the in situ measurements of number, surface-area, and volume concentrations, and effective radii for DAQ CA (left) and DAQ TX (right) with and without the hygroscopic correction applied to the in situ measurements. The boxplots represent the distribution of the biases observed between the HSRL-2 retrievals and the in situ measurements for each parameter. The relative bias was calculated as the ratio of the difference between HSRL-2 retrievals and the in situ measurements $(\Delta x)$ to the average between the HSRL-2 retrievals and the in situ measurements $(\bar{x})$. The red line represents the median value, the boxes edges represent the $25^{t h}$ and $75^{t h}$ percentiles $\left(q_{1}, q_{3}\right.$, respectively), and the whiskers represent $\left(q_{1}-1.5 \times \mathrm{IQR}\right)$ and $\left(q_{1}+1.5 \times \mathrm{IQR}\right)$, where $\mathrm{IQR}$ is the interquartile range, defined as IQR $=q_{3}-q_{1}$. 
Atmos. Chem. Phys. Discuss., doi:10.5194/acp-2016-380, 2016

Manuscript under review for journal Atmos. Chem. Phys.

Published: 17 May 2016

(c) Author(s) 2016. CC-BY 3.0 License.

(c) (i)
Atmospheric

Chemistry

and Physics

Discussions
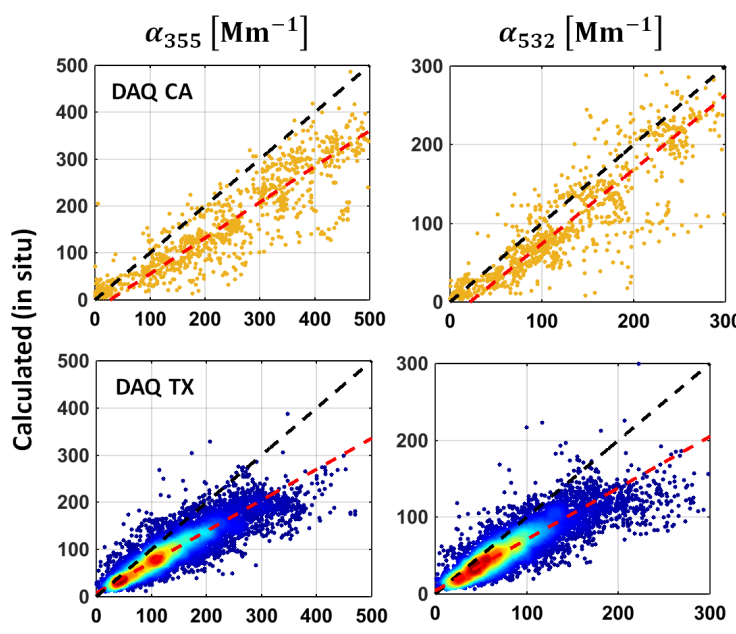
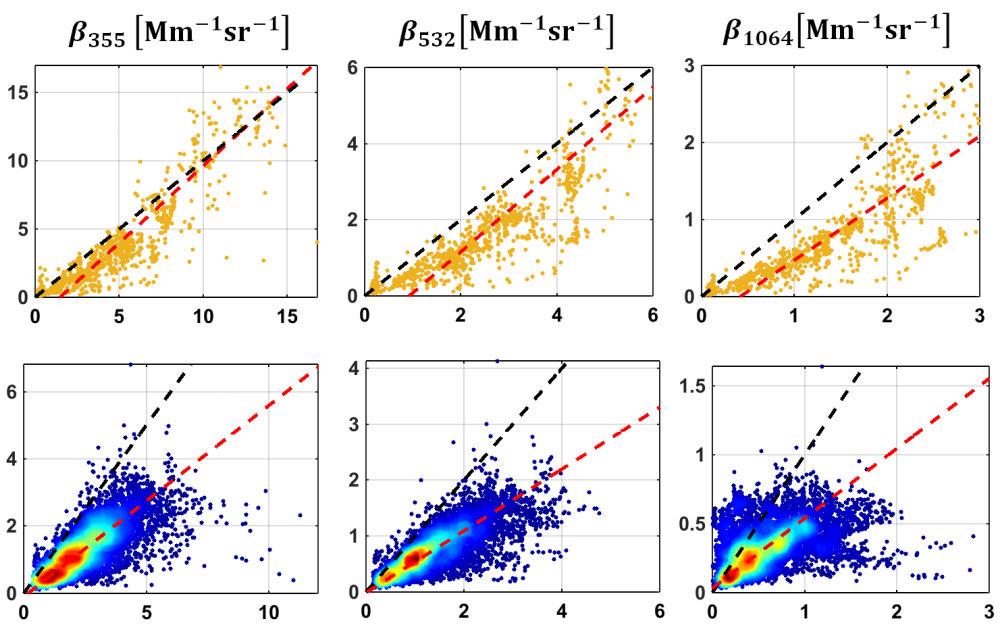

HSRL-2

Figure 7. Comparison between calculated and measured $3 \beta+2 \alpha$. The measurements obtained with the HSRL-2 are on the $\mathrm{x}-\mathrm{axis}$ and the optical parameters calculated from the adjusted in situ size distributions measured with the UHSAS (see text). The black dashed lines represent the 1:1 line and the red dashed lines correspond to bisector linear regression fit of each dataset (see Table 3 for fit parameters). DAQ TX data are presented as scatter density plots. 
Atmos. Chem. Phys. Discuss., doi:10.5194/acp-2016-380, 2016

Manuscript under review for journal Atmos. Chem. Phys.

Published: 17 May 2016

(c) Author(s) 2016. CC-BY 3.0 License.
Atmospheric

Chemistry

and Physics

Discussions

(c) $\underset{\mathrm{Br}}{(\mathrm{i}}$
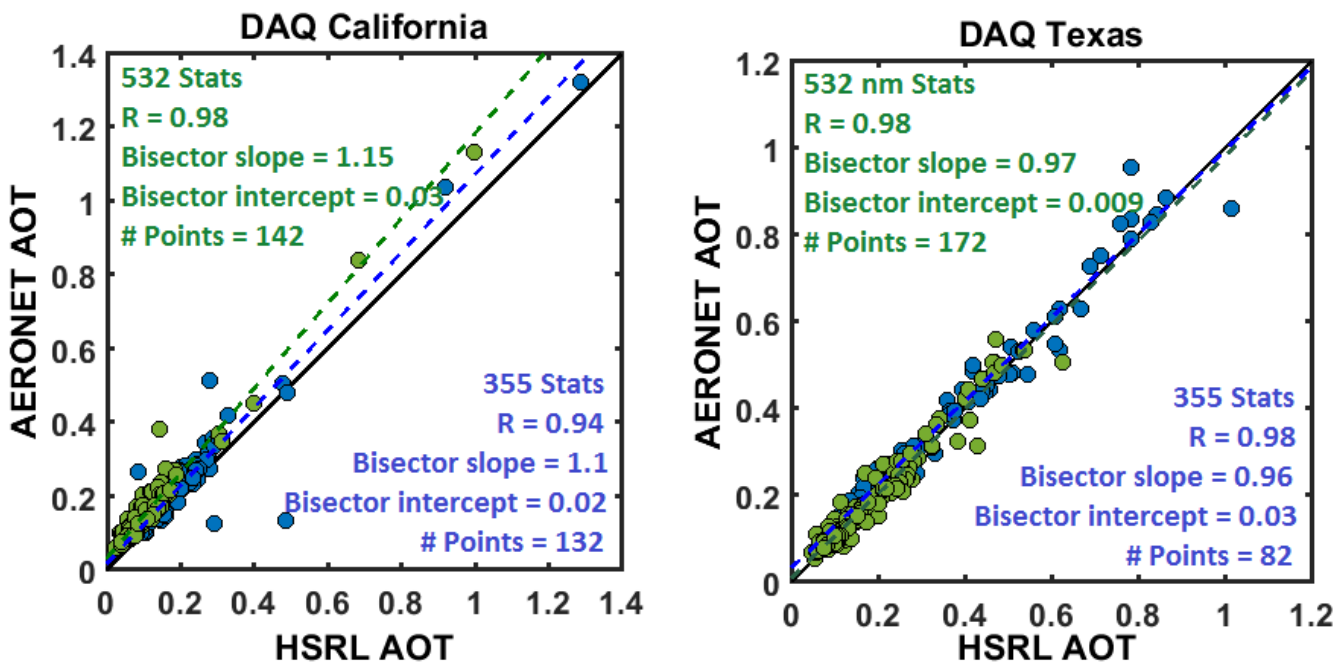

\section{1:1 Line AOT $355 \mathrm{~nm}$ ○ \\ - - - Least-square bisector - 355nm - - - Least-square bisector $-532 \mathrm{~nm}$}

Figure 8. Comparison of AOT measurements at 355 and $532 \mathrm{~nm}$ measured with HSRL-2 and AERONET/DRAGON sunphotometers during DAQ California (left) and DAQ Texas (right). Measurements from AERONET were calculated from level 2.0 measurements of AOT at $340 \mathrm{~nm}$ and $500 \mathrm{~nm}$, corrected to 355 and $532 \mathrm{~nm}$ using Ångström exponents calculated between 340 and $440 \mathrm{~nm}$, and 440 and $675 \mathrm{~nm}$, respectively. Only measurements obtained within a radius of $2.5 \mathrm{~km}$ and 10 minutes from each other were considered.

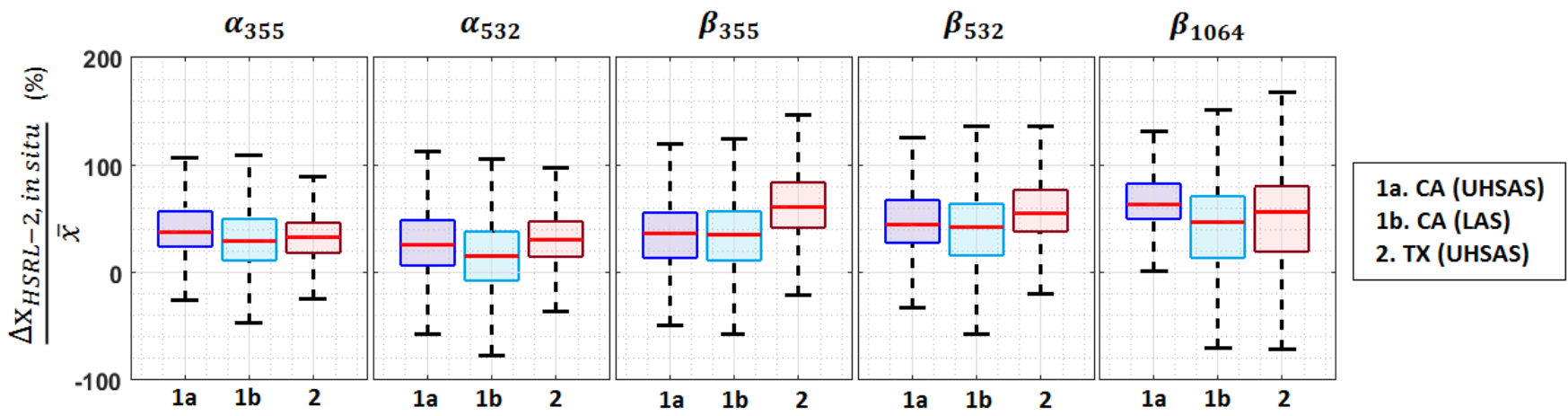

Figure 9. Statistics of bias observed between HSRL-2 measurements of extinction $(\alpha)$ and backscatter coefficients $(\beta)$ and those calculated from the adjusted in situ measurements and Mie theory for the DAQ CA data (using UHSAS and LAS) and for the DAQ TX data (UHSAS only). UHSAS measures the size distribution of sub-micron particles, while the LAS measures the size distribution of sub- and super-micron particles. 
Atmos. Chem. Phys. Discuss., doi:10.5194/acp-2016-380, 2016

Manuscript under review for journal Atmos. Chem. Phys.

Published: 17 May 2016

(c) Author(s) 2016. CC-BY 3.0 License.

(c) (1)

\section{Atmospheric \\ Chemistry \\ and Physics \\ Discussions}
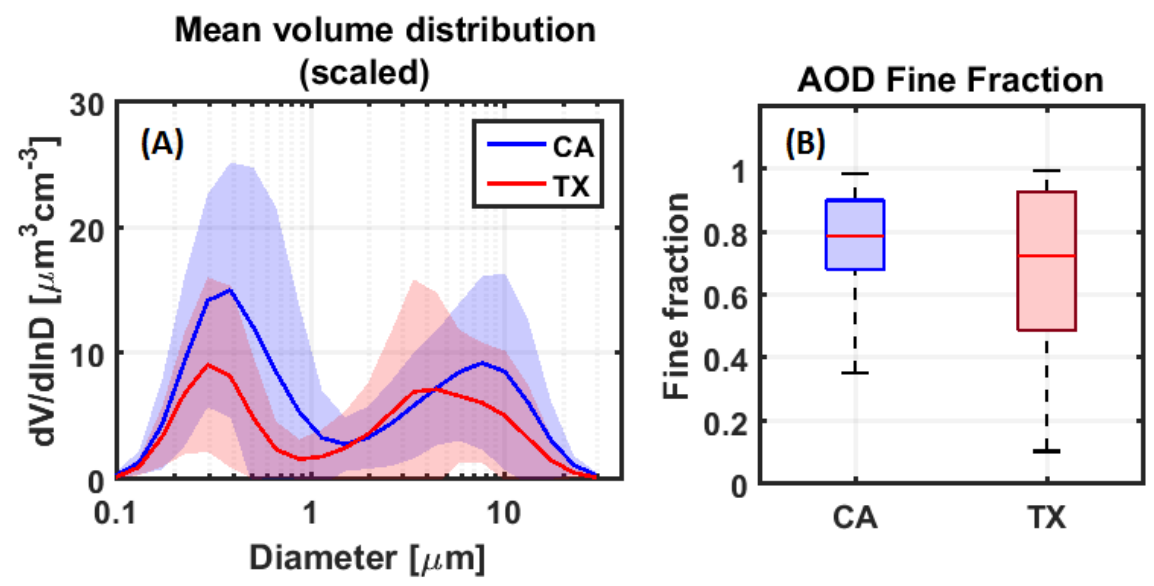

Figure 10. (A) Mean volume distribution retrieved from AERONET/DRAGON sunphotometer measurements, scaled to a maximum aerosol layer height of $1 \mathrm{~km}$ for CA and $3 \mathrm{~km}$ for Texas. (B) Statistics for the aerosol optical depth fine fraction. 
Atmos. Chem. Phys. Discuss., doi:10.5194/acp-2016-380, 2016

Manuscript under review for journal Atmos. Chem. Phys.

Published: 17 May 2016

(c) Author(s) 2016. CC-BY 3.0 License.
Atmospheric

Chemistry

and Physics

Discussions
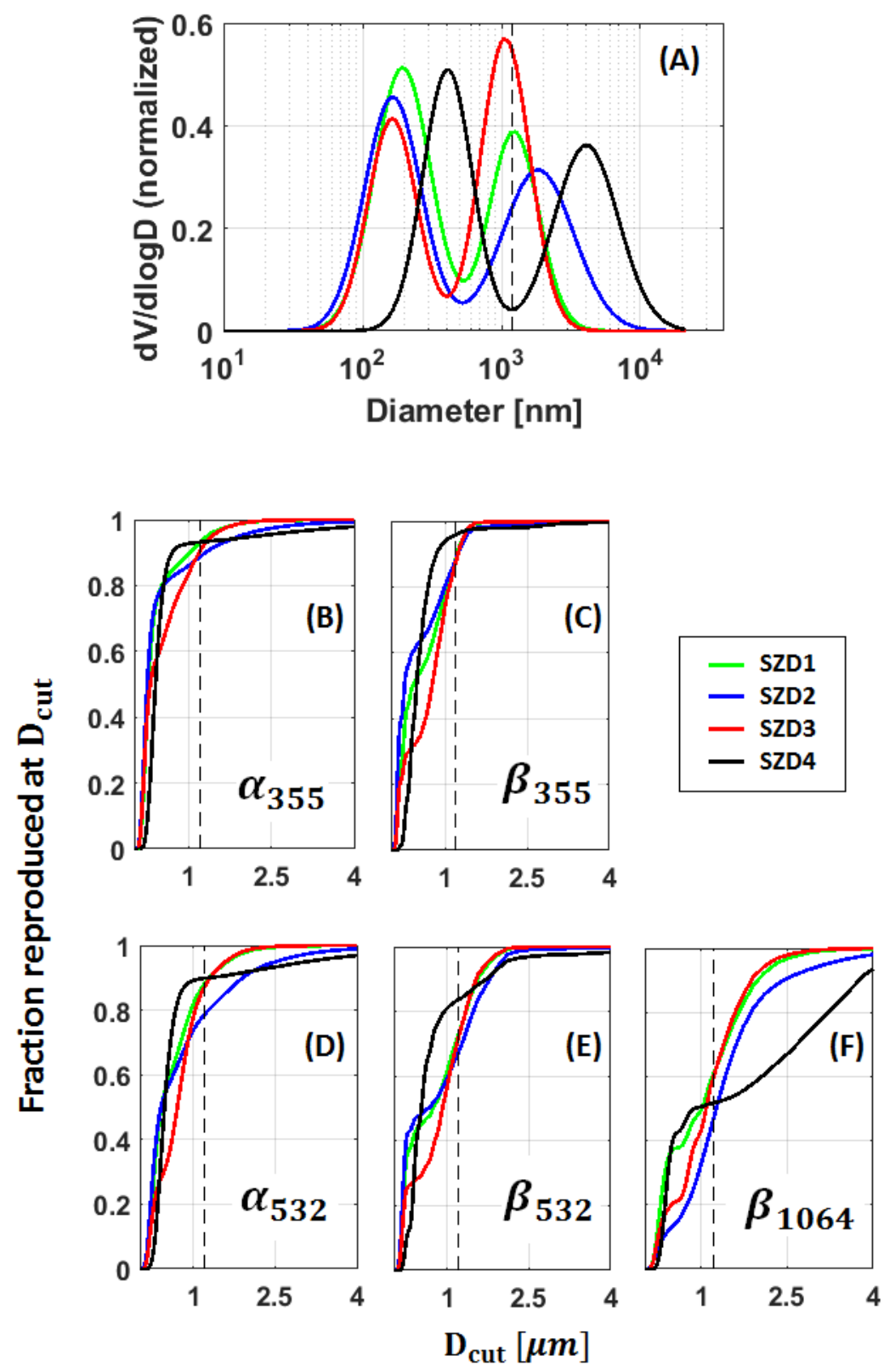

Figure 11. (A): Simulated size distributions (in volume) used to investigate the effect of cut-off sizes on measurement bias. Effective radius for SZD1-4 are: $0.26,0.25,0.30,0.66 \mu \mathrm{m}$. Fine mode effective radius (up to $1 \mu \mathrm{m}$ ) are: 0.20, 0.16, 0.21, 0.37 $\mu \mathrm{m}$. (B-F): Fraction of the extinction and backscatter coefficients ( $\alpha$ and $\beta$, respectively) that are able to be reproduced for varying cut-off diameters $\left(\mathrm{D}_{c u t}\right)$, i.e. $1=$ $100 \%$. The dashed vertical lines are references at $\mathrm{D}_{c u t}=1.2 \mu \mathrm{m}$. The values at this and other reference points are presented in Table 4 . The complex index of refraction used in this example was $\mathrm{m}_{R}=1.5, \mathrm{~m}_{i}=0.01$. 
Atmos. Chem. Phys. Discuss., doi:10.5194/acp-2016-380, 2016

Manuscript under review for journal Atmos. Chem. Phys.

Published: 17 May 2016

(c) Author(s) 2016. CC-BY 3.0 License.
Atmospheric

Chemistry

and Physics

Discussions

(c) (1)
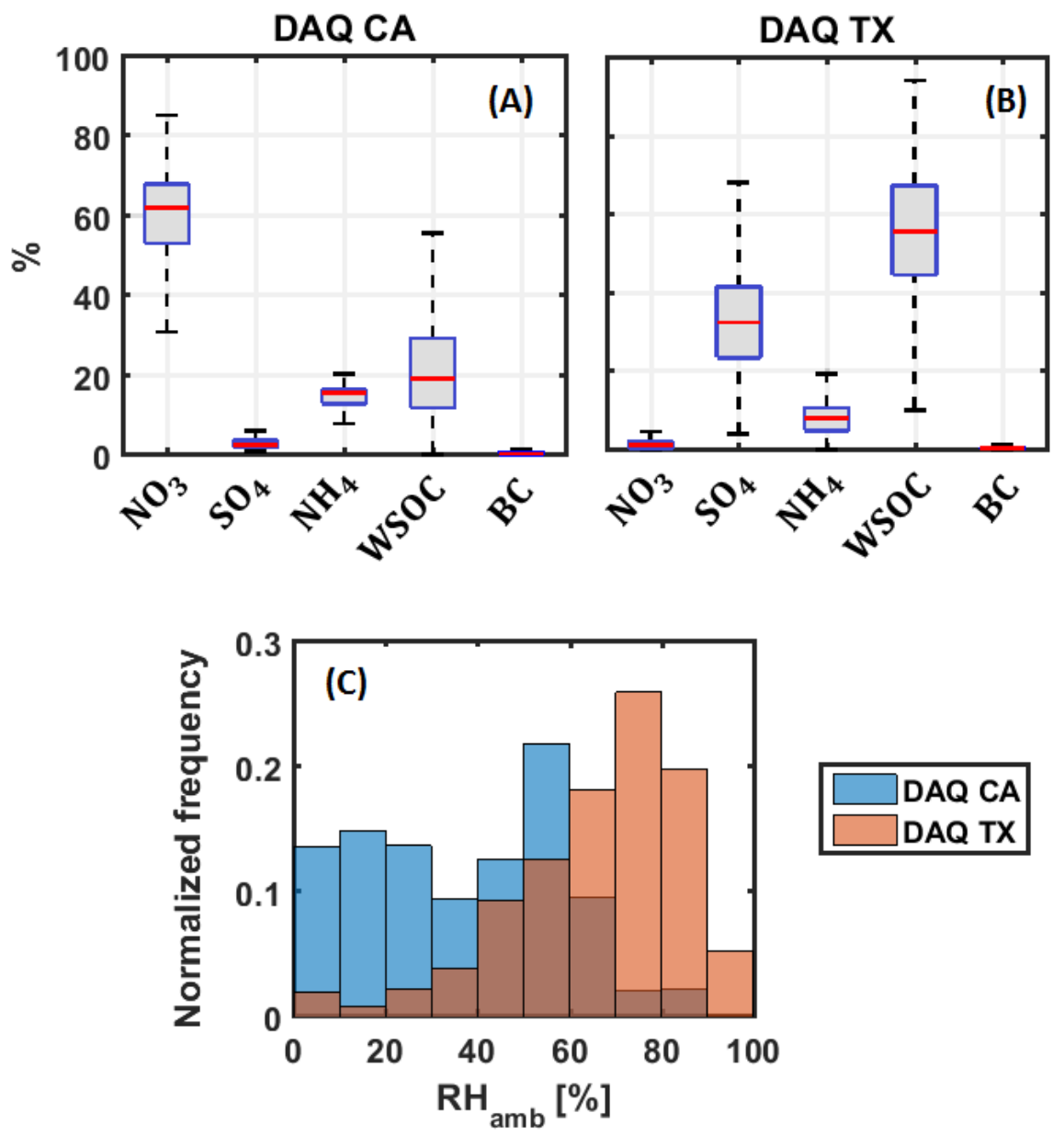

Figure 12. Relative aerosol composition measured with PILS for DAQ CA (A) and DAQ TX (B). The fractions were calculated with the assumption that the total mass was composed of $\mathrm{NO}_{3}, \mathrm{SO}_{4}, \mathrm{NH}_{4}$, WSOC and $\mathrm{BC}$ (black carbon). (C) Relative humidity measurements during DAQ CA and TX. 
Atmos. Chem. Phys. Discuss., doi:10.5194/acp-2016-380, 2016 Manuscript under review for journal Atmos. Chem. Phys.

Published: 17 May 2016

(C) Author(s) 2016. CC-BY 3.0 License.

(c) (i)

\section{Atmospheric \\ Chemistry and Physics \\ Discussions}

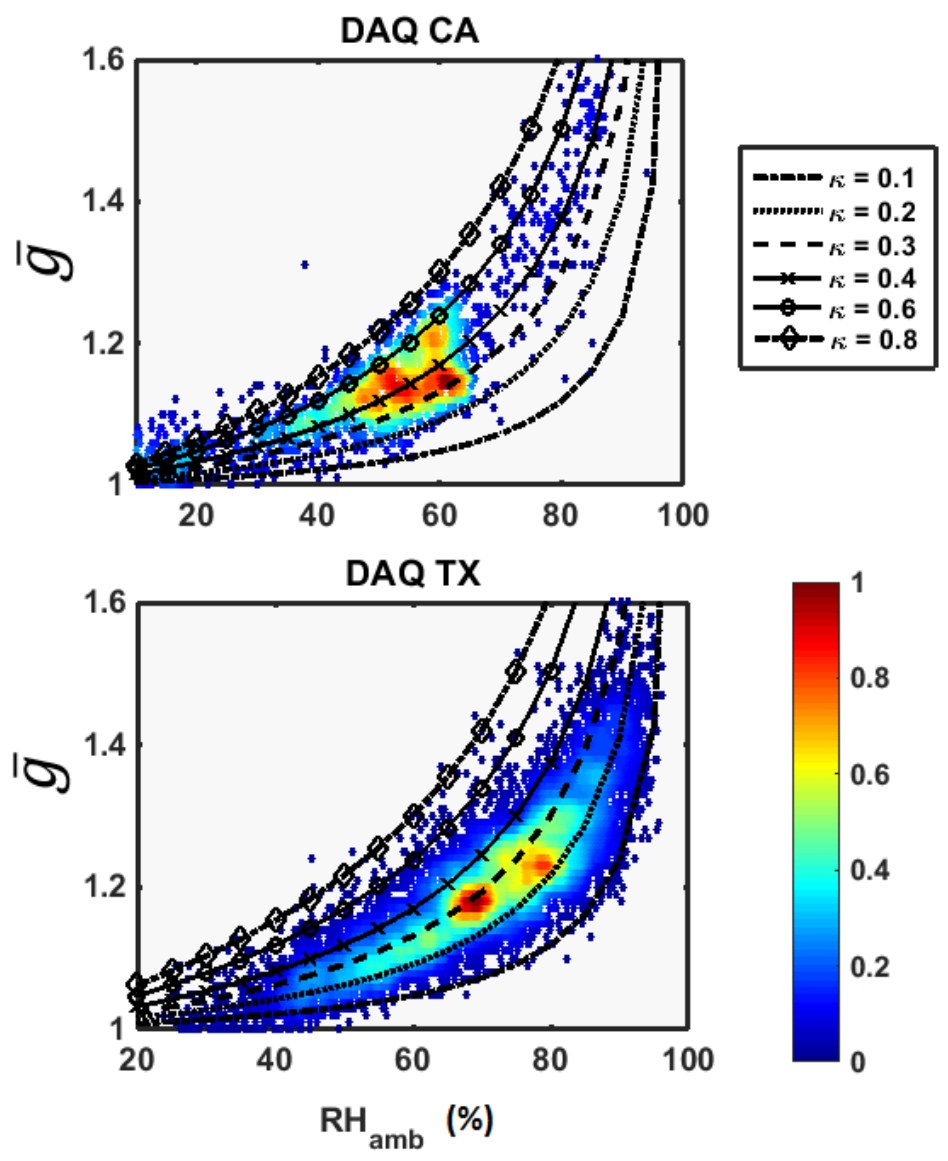

Figure A1. Relationship between retrieved $\bar{g}$ and measure RH. Each isoline represents a hygroscopicity parameter $\kappa$. Due to the large number of data points, the color scale represents data density and is normalized to 1 . 
Atmos. Chem. Phys. Discuss., doi:10.5194/acp-2016-380, 2016

Manuscript under review for journal Atmos. Chem. Phys.

Published: 17 May 2016

(c) Author(s) 2016. CC-BY 3.0 License.
Atmospheric

Chemistry

and Physics

Discussions

(c) (i)
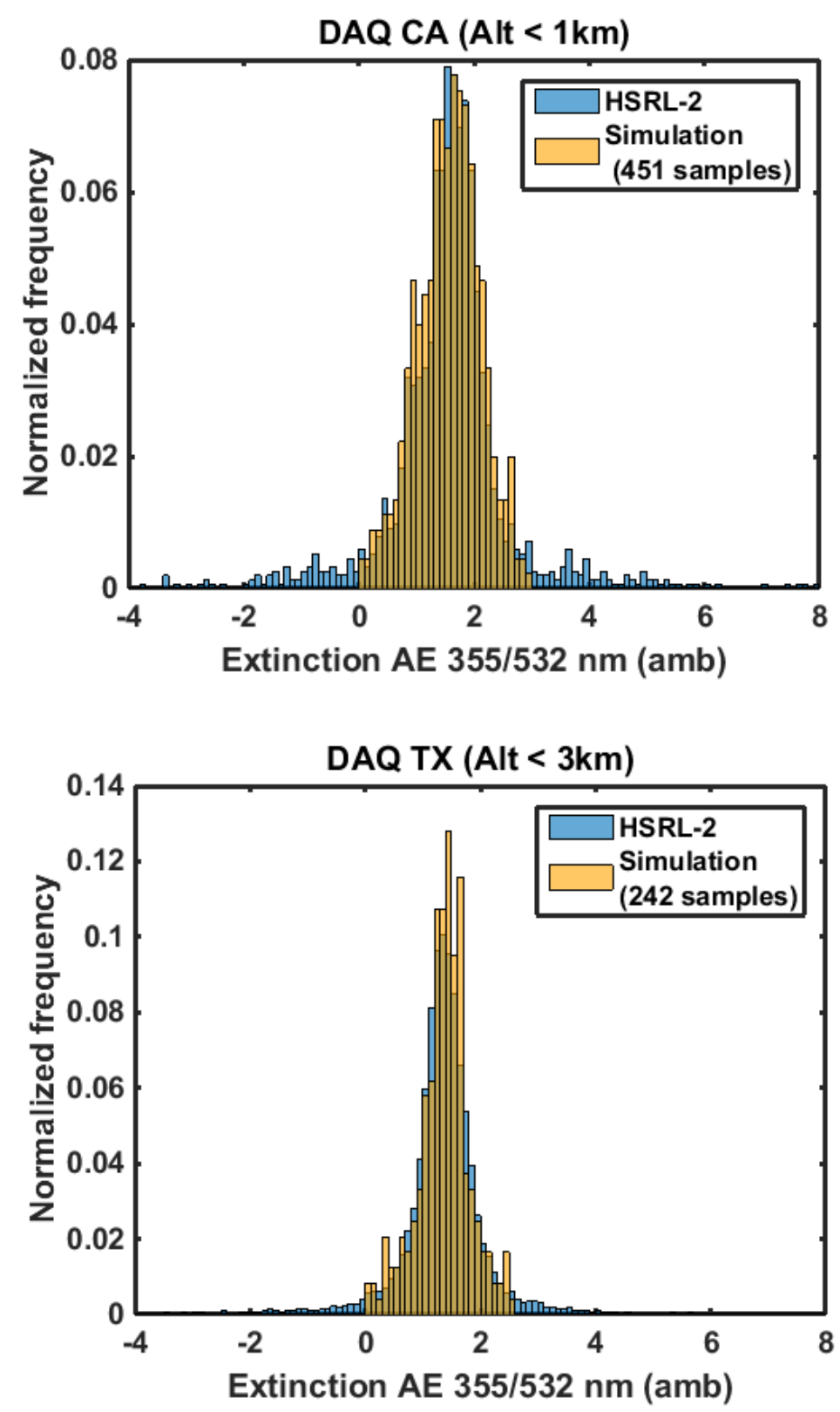

Figure A2. Distribution of Ångström exponents between $355 \mathrm{~nm}$ and $532 \mathrm{~nm}$ from HSRL-2 measurements and simulations used for the evaluation of the algorithm that retrieves complex index of refraction and effective growth factors from the in situ measurements. 